\author{
Angelo Licastro \\ (professore ordinario di Diritto ecclesiastico nell'Università degli Studi di \\ Messina, Dipartimento di Giurisprudenza)
}

\title{
Il rapporto di lavoro degli insegnanti di religione nelle scuole pubbliche italiane davanti alla Corte di giustizia dell'Unione europea *
}

\section{The Employment Relationship of Religious Education Teachers in Italian State Schools before the Court of Justice of the European Union *}

\begin{abstract}
The Italian legislation excludes the transformation of successive fixed-term contracts into contracts of indefinite duration in the teaching sector. This also applies to Catholic religious education teachers. The present paper analyses the decision of the Court of Justice of the European Union in case C$282 / 19$, which dealt with the issue of the compatibility of such a rule with the framework agreement on fixed-term work concluded by ETUC, UNICE and CEEP (annexed to Council Directive 1999/70/EC of 28 June 1999) and with the prohibition of discrimination on grounds of religion (Article 21 of the Charter of Fundamental Rights of the European Union; Council Directive 2000/78/EC of 27 November 2000). According to the Author, the Court's final indication for the referring court, to verify whether an interpretation of the national provisions which is consistent with the framework agreement is possible, is not easily practicable, because the "obligation on a national court to refer to the content of a directive when interpreting and applying the relevant rules of domestic law [...] cannot serve as the basis for an interpretation contra legem", as noted by the Court.
\end{abstract}

SOMMARIO: 1. La direttiva 1999/70/CE del Consiglio del 28 giugno 1999 relativa all'accordo quadro CES, UNICE e CEEP sul lavoro a tempo determinato e i meccanismi di definizione della politica sociale europea - 2. Cenni sulla disciplina generale del rapporto di lavoro a tempo determinato risultante dal decreto legislativo 6 settembre 2001, n. 368, attuativo della direttiva 1999/70/CE, e dal decreto legislativo 15 giugno 2015, n. 81 - 3. La posizione ricoperta dall'insegnante di religione nell'ambito dell'ordinamento del personale docente della scuola - 4 . La vertenza riguardante gli insegnanti di religione cattolica e le questioni pregiudiziali sottoposte alla Corte di giustizia - 5. L'eventuale incidenza

* Contributo sottoposto a valutazione - Article peer evaluated.

Il testo della sentenza 13 gennaio 2022 della Corte di Giustizia dell'Unione Europea (ripreso dal sito https:/curia.europa.eu/juris/document/document_print.jsf?docid=252122Etext $=\mathcal{E}$ dir $=\mathcal{E}$ doclang $=I T \mathcal{E}$ part $=1 \mathcal{E} o c c=$ first $\mathcal{E}$ mode $=$ reqE $\operatorname{EpageIndex}=0 \mathcal{E} c i d=230187$ ) è riportato in calce per comodità del lettore. 
dell'impegno dell'Unione a salvaguardare lo status previsto per le confessioni religiose dal diritto nazionale (art. 17 TFUE) - 6. La tutela antidiscriminatoria degli insegnanti di religione: $a$ ) l'assenza di una discriminazione per motivi di religione rispetto alla posizione degli altri supplenti della scuola pubblica - 7. (segue) b) L'inapplicabilità della clausola 4 dell'Accordo quadro - 8. La prevenzione degli abusi della successione dei contratti a tempo determinato per gli insegnanti di religione: in particolare le "ragioni obiettive" che possono giustificare il rinnovo 9. Conclusioni.

\section{1 - La direttiva 1999/70/CE del Consiglio del 28 giugno 1999 relativa all'accordo quadro CES, UNICE e CEEP sul lavoro a tempo determinato e $\mathrm{i}$ meccanismi di definizione della politica sociale europea}

Il cuore della questione oggetto del rinvio pregiudiziale sul quale si è pronunziata la Corte di giustizia con la sentenza da cui trae spunto il presente scritto ${ }^{1}$, da collocare all'interno di un filone giurisprudenziale già noto $^{2}$, attiene alla materia della politica sociale e dell'occupazione, che ha visto, negli ultimi anni, ampliarsi gli ambiti di intervento da parte dell'Unione europea, con un coinvolgimento attivo anche delle organizzazioni sindacali.

Si parla, ormai, comunemente, di "dialogo sociale europeo" per indicare sia i rapporti che i sindacati dei lavoratori e i rappresentanti dei datori di lavoro nazionali intrattengono con le organizzazioni riconosciute al livello europeo, sia il contributo da essi offerto alla definizione delle politiche europee in materia sociale e di occupazione attraverso la contrattazione e la stipula di veri e propri accordi ${ }^{3}$.

\footnotetext{
${ }^{1}$ Corte di giustizia U.E., sez. II, 13 gennaio 2022, causa C-282/19, YT e altri c. Ministero dell'Istruzione, dell'Università e della Ricerca - MIUR, Ufficio Scolastico Regionale per la Campania.

2 Strette similitudini si colgono con Corte di giustizia U.E, sez. III, 26 novembre 2014, cause riunite C-22/13, da C-61/13 a C-63/13 e C-418/13, Mascolo e altri c. Ministero dell'Istruzione, dell'Università e della Ricerca e Comune di Napoli, riguardante le supplenze nei posti vacanti e disponibili privi di titolare in attesa di espletamento dei concorsi del personale precario della scuola. Su tale pronunzia, tra gli altri, cfr. L. CALAFÀ, Il dialogo multilevel tra Corti e la "dialettica prevalente": le supplenze scolastiche al vaglio della Corte di giustizia, in Riv. it. di dir. del lav., 2015, n. 1, II, p. 336 ss.; L. MENGHINI, Sistema delle supplenze e parziale contrasto con l'accordo europeo: ora cosa succederà?, ivi, p. 343 ss.

3 P. TOMASSETTI, B. WINKLER, Il ruolo delle parti sociali nella fase ascendente del diritto dell'Unione europea, in Dir. delle relaz. industr., 2012, n. 2, p. 481. Tale contributo si sviluppa attraverso «un'ampia gamma di procedure e contenuti: la consultazione delle
} 
Dopo le timide aperture presenti nell'Atto unico europeo (1986), che ha offerto la prima base giuridica per l'edificazione di un tale assetto ${ }^{4}$, affidando alla Commissione il compito di "sviluppare a livello europeo un dialogo tra le parti sociali, il quale possa sfociare, se esse lo ritengono opportuno, in relazioni convenzionali" (art. 22), una tappa fondamentale nell'evoluzione di questi meccanismi è rappresentata dalla Dichiarazione comune del 31 ottobre 1991 tra l'Unione delle Confederazioni Europee dell'Industria e dei Datori di lavoro (UNICE), il Centro Europeo delle Imprese pubbliche (CEEP) e la Confederazione Europea dei Sindacati (CES), che verrà poi sostanzialmente recepita nell'Accordo sulla politica sociale (1992)5, annesso all'omonimo Protocollo (n. 14) allegato al Trattato che istituisce la Comunità europea.

L'art. 4 del menzionato Accordo sulla politica sociale, oltre a prevedere che il dialogo fra le parti sociali a livello comunitario potesse condurre a relazioni contrattuali, finalizzate anche alla stipula di accordi (art. 4, par. 1), stabilirà che gli accordi conclusi a livello comunitario sono attuati secondo le procedure e la prassi proprie delle parti sociali e degli Stati membri o, nell'ambito dei settori contemplati dall'articolo 2, e a richiesta congiunta delle parti firmatarie, in base a una decisione del Consiglio su proposta della Commissione (art. 4, par. 2)6.

organizzazioni rappresentative in ambito europeo dei lavoratori e dei datori di lavoro da parte delle istituzioni, la concertazione, le procedure di dialogo sociale "in senso stretto", ovvero di valorizzazione dell'autonomia negoziale ed il coinvolgimento dei soggetti collettivi nel processo legislativo comunitario»: M. MARTONE, Sindacato europeo e contrattazione collettiva, in Diritto del lavoro. Commentario diretto da Franco Carinci, Vol. IX, Diritto del lavoro dell'Unione Europea, a cura di A. PIZZOFERRATO, F. CARINCI, Utet Giuridica, Milanofiori Assago, 2010, p. 785. Sull'evoluzione del dialogo sociale europeo, cfr., altresì, A. ALAIMO, B. CARUSO, Dialogo sociale e negoziazione collettiva nell'ordinamento europeo (parte I), in ADL Argomenti di diritto del lavoro, 2012, 6/1, p. 1123 ss.

${ }^{4}$ Cfr. M. MARTONE, Sindacato europeo, cit., p. 787.

${ }^{5}$ Trattato sull'Unione europea - Accordo sulla politica sociale concluso tra gli Stati membri della Comunità europea a eccezione del Regno Unito di Gran Bretagna e Irlanda del Nord, in Gazzetta ufficiale delle comunità europee 29 luglio 1992, n. C 191, p. 91 ss.

${ }^{6}$ In tal modo, come è stato scritto, si introduce una procedura "che prende le mosse dalla consultazione, da parte della Commissione, delle parti sociali e che può condurre non solo alla semplice cooperazione nella fase di proposta legislativa, ma anche alla disciplina di una specifica materia da parte delle parti sociali, con conseguente autolimitazione da parte della Commissione": M. MARTONE, Sindacato europeo, cit., p. 789. Si segnala che il contenuto di queste disposizioni è stato dapprima trasposto negli artt. 136-145 del Trattato che istituisce la comunità europea (TCE) e ora negli artt. 151-161 del Trattato sul funzionamento dell'Unione europea (TFUE). 
È in base a questo meccanismo che verrà concluso, il 18 marzo 1999, dalle organizzazioni intercategoriali a carattere generale UNICE, CEEP e CES, l'accordo quadro sul lavoro a tempo determinato attuato con la direttiva 1999/70/CE del Consiglio e assunto nel giudizio nazionale, nel corso del quale è stata proposta la questione pregiudiziale decisa dalla Corte di giustizia, a parametro di legittimità della disciplina italiana riguardante il rapporto di lavoro degli insegnanti di religione cattolica nelle scuole pubbliche.

La Carta comunitaria dei diritti sociali fondamentali dei lavoratori, adottata nel 1989, nel fissare i principi fondamentali su cui si basa il diritto del lavoro europeo, ribadiva al punto 7 che l'obiettivo del miglioramento delle condizioni di vita e di lavoro nell'ambito della Comunità europea, da realizzare attraverso "il ravvicinamento di tali condizioni, che costituisca un progresso", deve, anzitutto, interessare, oltre alla durata e all'organizzazione dell'orario di lavoro, "le forme di lavoro diverse dal lavoro a tempo indeterminato, come il lavoro a tempo determinato, il lavoro a tempo parziale, il lavoro temporaneo e il lavoro stagionale"7. Come ricordato nel considerando n. 5 e in quello n. 6 della direttiva, essa intende dare seguito agli orientamenti emersi dal Consiglio europeo di Essen del 1995 - che avevano sottolineato

«la necessità di provvedimenti per “incrementare l'intensità occupazionale della crescita, in particolare mediante un'organizzazione più flessibile del lavoro, che risponda sia ai desideri dei lavoratori che alle esigenze della competitività"»-

ripresi poi da una risoluzione del Consiglio del 9 febbraio 1999, che

"invita le parti sociali a tutti i livelli appropriati a negoziare accordi per modernizzare l'organizzazione del lavoro, comprese forme flessibili di lavoro, al fine di rendere le imprese produttive e competitive e di realizzare il necessario equilibrio tra la flessibilità e la sicurezza".

Nel Preambolo all'Accordo quadro attuato dalla direttiva in esame, recepita nel nostro ordinamento col decreto legislativo 6 settembre 2001, n. 368 , si precisa che esso

"stabilisce i principi generali e i requisiti minimi relativi al lavoro a tempo determinato, riconoscendo che la loro applicazione dettagliata

${ }^{7}$ COMMISSIONE DELLE COMUNITÀ EUROPEE, Carta comunitaria dei diritti sociali fondamentali dei lavoratori, adottata dai Capi di Stato o di Governo degli Stati membri della Comunità europea riuniti a Strasburgo, il 9 dicembre 1989, Lussemburgo, Ufficio delle pubblicazioni ufficiali delle Comunità europee, 1990, p. 14. 
deve tener conto delle realtà specifiche delle situazioni nazionali, settoriali e stagionali. Esso indica la volontà delle parti sociali di stabilire un quadro generale che garantisca la parità di trattamento ai lavoratori a tempo determinato, proteggendoli dalle discriminazioni, e un uso dei contratti di lavoro a tempo determinato accettabile sia per i datori di lavoro sia per i lavoratori".

Ma, come si vedrà meglio più oltre, l'incidenza dell'Accordo sulla disciplina del contratto di lavoro a termine è alquanto più circoscritta $\mathrm{e}$ marginale di quanto sembrerebbe a prima vista risultare da tali impegnative affermazioni.

\section{2 - Cenni sulla disciplina generale del rapporto di lavoro a tempo determinato risultante dal decreto legislativo 6 settembre 2001, n. 368, attuativo della direttiva 1999/70/CE, e dal decreto legislativo 15 giugno 2015, n. 81}

Prima di illustrare le specifiche questioni pregiudiziali sottoposte all'esame della Corte di giustizia, può essere utile qualche cenno introduttivo sulla evoluzione della disciplina generale del rapporto di lavoro a tempo determinato nel nostro ordinamento e sul ruolo da questo attualmente ricoperto nel mercato del lavoro rispetto al modello concorrente del rapporto a tempo indeterminato.

Il decreto legislativo 6 settembre 2001, n. 368, in attuazione della direttiva in esame, aveva dettato una nuova disciplina dei rapporti di lavoro a tempo determinato, superando quella derivante dalla precedente legge 18 aprile 1962 , n. $230^{8}$.

In estrema sintesi, mentre la precedente normativa si basava sulla specifica individuazione tassativa delle situazioni in cui (del tutto eccezionalmente) doveva ritenersi consentita l'apposizione di un termine al rapporto di lavoro (senza, peraltro, fare in alcun modo cenno alla peculiare situazione degli insegnanti di religione cattolica nelle scuole pubbliche), l'art. 1 del decreto legislativo n. 368 del 2001 rinviava, invece, a generiche "ragioni di carattere tecnico, produttivo, organizzativo o sostitutivo" per la circoscrizione di quelle situazioni. In tal modo, sembravano "superati i caratteri della "eccezionalità", "straordinarietà" ed "imprevedibilità" propri delle precedenti ragioni giustificatrici» 9 ; ma parte

${ }^{8}$ La legge del 1962 è stata abrogata dall'art. 11 del decreto legislativo n. 368 del 2001.

${ }^{9}$ Circolare del Ministro del lavoro e delle politiche sociali n. 42 del $1^{\circ}$ agosto 2002. 
della dottrina ${ }^{10}$ insistette nell'individuare ancora, quale irrinunciabile elemento identificativo del contratto di lavoro a termine, il carattere della "temporaneità" delle suddette ragioni giustificatrici, il quale non sarebbe, però, riuscito a imporsi, nella pratica giuridica concreta, come oggettivo criterio di qualificazione efficacemente utilizzabile; tanto che, stando ai chiarimenti diramati al livello ministeriale, la stipulazione di un contratto a termine doveva ormai intendersi svincolata dal suddetto presupposto dell'esecuzione di prestazioni aventi il carattere della "temporaneità", anche se tutto questo non autorizzava a ritenere come (del tutto) prive di contenuto oggettivo e verificabile le cause giustificatrici fissate dal decreto $^{11}$. In linea di principio, la normativa in esame poteva trovare applicazione anche nel settore del pubblico impiego, sia pure solo in presenza, come ribadito dal legislatore, di "comprovate esigenze di carattere esclusivamente temporaneo o eccezionale"12.

La preferenza dell'ordinamento per il contratto a tempo indeterminato risultava confermata dai limiti temporali che venivano imposti alla fissazione del termine di durata dell'altra tipologia di contratti, comminando, per il caso di violazione, la sanzione della conversione del rapporto, nato con un contratto a termine e destinato a proseguire come rapporto a tempo indeterminato. Se, infatti, il rapporto di lavoro continuava per un certo periodo, variamente definito in rapporto alla diversa durata pattuita, oltre il termine fissato per quest'ultima, il contratto si considerava automaticamente a tempo indeterminato ${ }^{13}$. Sanzione, tuttavia, non applicabile nel settore del pubblico impiego, in

10 La si può vedere richiamata in G. LUDOVICO, Contratto a tempo determinato versus contratto a tutele crescenti: gli obiettivi e $i$ risultati del Jobs Act tra flessibilità e incentivi economici, in Dir. delle relaz. industr., n. 1, 2018, p. 65 s.

11 Circolare del Ministro del lavoro e delle politiche sociali del $1^{\circ}$ agosto 2002 , cit. La circolare precisava a questo riguardo che "la temporaneità della prestazione è, semplicemente, la dimensione in cui deve essere misurata la ragionevolezza delle esigenze tecniche, organizzative, produttive o sostitutive poste a fondamento della stipulazione del contratto a tempo determinato. Il contratto a termine dovrà pertanto essere considerato lecito in tutte le circostanze, individuate dal datore di lavoro sulla base di criteri di normalità tecnico-organizzativa ovvero per ipotesi sostitutive, nelle quali non si può esigere necessariamente una assunzione a tempo indeterminato $\mathrm{o}$, il che è lo stesso, l'assunzione a termine non assuma una finalità chiaramente fraudolenta sulla base di criteri di ragionevolezza desumibili dalla combinazione tra durata del rapporto e attività lavorativa dedotta in contratto".

12 Art. 36, secondo comma, del decreto legislativo 30 marzo 2001, n. 165 (Norme generali sull'ordinamento del lavoro alle dipendenze delle amministrazioni pubbliche).

${ }^{13}$ Art. 5, commi secondo e 4-bis, del decreto legislativo n. 368 del 2001. 
relazione al quale è previsto che

\begin{abstract}
"[i]n ogni caso, la violazione di disposizioni imperative riguardanti l'assunzione o l'impiego di lavoratori, da parte delle pubbliche amministrazioni, non può comportare la costituzione di rapporti di lavoro a tempo indeterminato con le medesime pubbliche amministrazioni, ferma restando ogni responsabilità e sanzione. Il lavoratore interessato ha diritto al risarcimento del danno derivante dalla prestazione di lavoro in violazione di disposizioni imperative" 14 .
\end{abstract}

Restavano, in ogni caso, esclusi dal campo di applicazione del decreto legislativo alcuni rapporti di lavoro già disciplinati da specifiche normative, come nel caso del settore del turismo o dell'agricoltura (art. 10, commi 1-6). Veniva poi affidata la individuazione di limiti quantitativi di utilizzazione dell'istituto ai contratti collettivi nazionali di lavoro stipulati dai sindacati comparativamente più rappresentativi, esentando in ogni caso da tali vincoli alcune particolari tipologie di contratti a tempo determinato (art. 10, commi 7-8).

Senza dubbio, la disciplina del contratto di lavoro a termine contenuta nel decreto legislativo n. 368 del 2001 aveva (o aspirava ad avere) carattere tendenzialmente esaustivo, riguardando l'intera materia oggetto di regolamentazione. Per questo si era ritenuto di dovere escludere "intersezioni applicative con le precedenti disposizioni che nel nuovo assetto normativo sono, pertanto, direttamente [...] o indirettamente abrogate"15.

Mentre tra la legge del 1962 e il decreto n. 368 del 2001 sono passati

14 Art. 36, comma 5, del decreto legislativo n. 165/2001.

${ }^{15}$ Circolare del Ministro del lavoro e delle politiche sociali del $1^{\circ}$ agosto 2002 , cit. L'art. 11, comma 1, del decreto legislativo n. 368 del 2001 prevedeva, infatti, l'abrogazione di "tutte le disposizioni di legge che sono comunque incompatibili e non sono espressamente richiamate nel presente decreto legislativo". Peraltro, con l'art. 10, comma 4-bis, del decreto legislativo n. 368 del 2001 , inserito dall'art. 9, comma 18, del d.-1. 13 maggio 2011, n. 70, convertito con modificazioni nella 1. 12 luglio 2011, n. 106 e successivamente modificato dall'art. 4, comma 11, del d.-1. 31 agosto 2013, n. 101, convertito nella 1. 30 ottobre 2013, n. 101, verrà previsto che, "[s]tante quanto stabilito dalle disposizioni di cui all'articolo 40, comma 1, della legge 27 dicembre 1997, n. 449, e successive modificazioni, all'articolo 4, comma 14-bis, della legge 3 maggio 1999, n. 124, e all'articolo 6, comma 5, del decreto legislativo 30 marzo 2001, n. 165, sono altresì esclusi dall'applicazione del presente decreto i contratti a tempo determinato stipulati per il conferimento delle supplenze del personale docente ed ATA, considerata la necessità di garantire la costante erogazione del servizio scolastico ed educativo anche in caso di assenza temporanea del personale docente ed ATA con rapporto di lavoro a tempo indeterminato ed anche determinato. [...]". 
quasi 40 anni, solo dopo 14 anni dall'entrata in vigore della normativa introdotta da quest'ultimo provvedimento, la disciplina del rapporto di lavoro a termine è stata interamente riscritta - in occasione dell'introduzione della riforma nota come "Jobs Act" - dagli artt. 19-29 del decreto legislativo 15 giugno 2015, n. 8116, attualmente vigente, sia pure rimaneggiato in alcuni punti da diversi interventi di modifica ${ }^{17}$, a riprova di una crescente difficoltà cui è andato incontro il legislatore, col trascorrere del tempo e con le trasformazioni che hanno via via interessato l'assetto del mercato del lavoro, "nell'individuare uno stabile punto di equilibrio tra l'esigenza di flessibilità delle imprese e l'aspirazione alla stabilità d'impiego dei lavoratori"18. In questo caso, l'obiettivo perseguito dal legislatore è stato "quello di modificare i rapporti di convenienza tra le fattispecie a tutto vantaggio del contratto a tempo indeterminato"19, attraverso il tentativo di rovesciare la situazione venutasi a determinare negli ultimi tempi, in cui al favor legislativo verso la stabilità e la durata indeterminata del rapporto, si è andata sovrapponendo una situazione di fatto caratterizzata da un ricorso sproporzionato al modello alternativo caratterizzato piuttosto da flessibilità e durata definita.

Con la disciplina introdotta dal decreto legislativo n. 81 del 2015, l'aspetto nuovo più dibattuto è senz'altro rappresentato dall'eliminazione del riferimento - pur generico, "aperto", di non limpida consistenza e non dotato di elevata capacità selettiva - alle "ragioni di carattere tecnico, produttivo, organizzativo o sostitutivo" individuate dall'art. 1 del decreto legislativo n. 368 del 2001.

In questo modo, a giudizio di molti Autori, sarebbe venuto meno l'ultimo argine, sottoponibile al controllo del giudice, capace di porre un qualche freno all'espansione incontrollata dei contratti a termine, destinati altrimenti a tramutarsi da eccezione a regola, in palese contrasto con le

16 Disciplina organica dei contratti di lavoro e revisione della normativa in tema di mansioni, a norma dell'articolo 1, comma 7, della legge 10 dicembre 2014, n. 183.

17 Sugli interventi da ultimo operati dal legislatore "per dare impulso al lavoro a termine muovendo dal presupposto che nella situazione attuale le perduranti incertezze dei mercati scoraggiano le assunzioni a tempo indeterminato, mentre per dare fiato all'occupazione si palesa necessario ricorrere ai CTD, anche in vista dell'attuazione del PNRR e dell'occupazione che auspicabilmente ne deriverà", cfr. A. MARESCA, Il contratto a termine nella fase post pandemica: archiviato o arricchito il Decreto Dignità? (prime osservazioni sull'art. 41-bis, l. n. 106/2021), in Labor, 2021, n. 4, p. 376 ss.

18 G. LUDOVICO, Contratto a tempo determinato, cit., p. 63.

${ }^{19}$ G. LUDOVICO, Contratto a tempo determinato, cit., p. 64. 
opposte indicazioni ricavabili dalla direttiva europea ${ }^{20}$. Si è piuttosto fissato un tetto percentuale calcolato sul complessivo numero di dipendenti, concepito come vero e proprio "limite legale che si sostituisce all'abolita regola della causalità" 21 , con l'effetto di spezzare qualsiasi nesso (qualitativo) tra natura dell'attività lavorativa e durata definita del rapporto di lavoro. In sostanza, il rapporto a tempo determinato viene ufficialmente riconosciuto e legittimato come elemento strutturale di organizzazione del lavoro, alimentando una sorta di "precarietà stabile" 22 costituita da una quota (minoritaria) di lavoratori che concorre con la figura capace di offrire le massime (sebbene ben più limitate rispetto al passato) garanzie di "reale" stabilità 23 .

Nulla autorizzerebbe, peraltro, secondo alcuni Autori, a ritenere per ciò solo violata la direttiva 1999/70/CE, in quanto essa, sebbene muova dal presupposto che " $\mathrm{i}$ contratti di lavoro a tempo indeterminato rappresentano la forma comune dei rapporti di lavoro e contribuiscono alla qualità della vita dei lavoratori interessati e a migliorare il rendimento" (considerando n. 6 dell'Accordo quadro) ${ }^{24}$, ha tuttavia come

${ }^{20}$ Cfr. M.V. BALLESTRERO, Così si scambia l'eccezione con la regola, in Lavoro Welfare, 2014, n. 4 , p. $13 \mathrm{~s}$.

${ }^{21}$ G. LUDOVICO, Contratto a tempo determinato, cit., p. 71.

${ }^{22}$ Riprendo questa locuzione da M. AIMO, Il lavoro a termine tra modello europeo e regole nazionali, con Prefazione di M.V. BALLESTRERO, Giappichelli, Torino, 2017, p. 1, utilizzata dall'Autrice «per qualificare buona parte del lavoro precario dei nostri giorni e più in particolare per descrivere il noto fenomeno della "trappola della precarietà" $[\ldots]$ in cui rischiano di cadere i lavoratori assunti con contratto non standard, senza prospettive di vera stabilità e a prezzo di una crescente vulnerabilità».

23 Secondo G. LUDOVICO, Contratto a tempo determinato, cit., p. 72, il limite quantitativo potrebbe garantire «una migliore attuazione anche del principio sancito dalla direttiva 1999/70/CE e ribadito dalla legge delega e dall'articolo 1 del decreto legislativo n. 81 del 2015, che definisce il contratto a tempo indeterminato come la "forma comune" di rapporto di lavoro, e ciò in quanto, a differenza della temporaneità, limiterebbe il ricorso al termine entro una quota minoritaria rispetto al contratto a tempo indeterminato che si porrebbe così come la fattispecie effettivamente prevalente». Al contrario, reputa che "i limiti percentuali, per come oggi risultano disciplinati, si rivelano fragili e dunque inidonei ad apprestare ai lavoratori a termine una reale ed effettiva tutela contro gli abusi nella stipula di contratti a termine successivi", M. AIMO, Il lavoro a termine, cit., p. 156 (e Autori ivi citati).

${ }^{24}$ Cfr. pure il primo inciso del secondo comma del Preambolo all'Accordo quadro, dove viene ribadito che "[l]e parti firmatarie dell'accordo riconoscono che i contratti a tempo indeterminato sono e continueranno ad essere la forma comune dei rapporti di lavoro fra i datori di lavoro e i lavoratori". Un "analogo favor nei confronti del lavoro a tempo indeterminato è [...] presente [...] anche nella direttiva n. 2008/104", in materia di lavoro tramite agenzia interinale: M. AIMO, Il lavoro a termine, cit., p. 19. 
unici obiettivi quello di "migliorare la qualità del lavoro a tempo determinato garantendo il rispetto del principio di non discriminazione" (in costanza di rapporto) e quello di "creare un quadro normativo per la prevenzione degli abusi derivanti dall'utilizzo di una successione di contratti o rapporti di lavoro a tempo determinato" (clausola 1 dell'Accordo quadro), senza incidere, dunque, in alcun modo sulle condizioni che consentono la stipula del primo contratto a tempo determinato del lavoratore ${ }^{25}$. Da segnalare che la sanzione della conversione del rapporto prevista per il caso di violazione dei limiti della durata massima era stata sostanzialmente confermata dal testo originario dell'art. 19, secondo comma, del decreto legislativo n. 81 del 2015 ed è tuttora prevista dal testo vigente della disposizione, con riferimento al nuovo limite massimo di durata fissato in 24 mesi $^{26}$.

L'elenco dei casi di non applicazione del decreto ricollegati a discipline specifiche riflette un "crescendo di esclusi dall'operatività dei limiti"27, indicando i numerosi regimi giuridici che derogano alla regola della preferenza per il rapporto di lavoro a tempo indeterminato. Per quel che interessa maggiormente in questa sede, figura ora un esplicito riferimento ai "contratti a tempo determinato stipulati con il personale docente ed ATA [personale amministrativo, tecnico e ausiliario] per il conferimento delle supplenze" [art. 29, secondo comma, lett. c)], che non risultavano espressamente indicati, come si è già accennato, nel testo originario del decreto legislativo n. 368 del 2001 .

\section{3 - La posizione ricoperta dall'insegnante di religione nell'ambito dell'ordinamento del personale docente della scuola}

Volendo, a questo punto, riassumere la posizione ricoperta dall'insegnante di religione nell'ambito dell'ordinamento del personale docente della scuola, bisogna distinguere, com'è noto, due fasi, la prima antecedente alla

\footnotetext{
25 Sul tema, tra i molti, M. AIMO, La nuova disciplina su lavoro a termine $e$ somministrazione a confronto con le direttive europee: assolto il dovere di conformità? in Giornale di dir. del lav. e delle relaz. industr., 2015, n. 148, p. 644 ss.; ID., Il lavoro a termine, cit. (con ampi riferimenti); V. LECCESE, La compatibilità della nuova disciplina del contratto di lavoro a tempo determinato con la direttiva n. 99/70, in Riv. giur. del lav., 2014, n. 4, I, p. 709 ss.

26 Art. 19, secondo comma, del decreto legislativo n. 81 del 2015, come modificato dall'art. 1, primo comma, lettera $a$ ), punto 2) del d.-1. 12 luglio 2018, n. 87, convertito con modificazioni nella 1.9 agosto 2018, n. 96.
}

${ }_{27}$ M. AIMO, Il lavoro a termine, cit., p. 156. 
legge 18 luglio 2003, n. 186, la seconda susseguente a essa.

Prima del 2003, e a partire dalla legge 5 giugno 1930, n. 824 - fonte di "carattere singolare e specifico", come il resto della normativa (di più o

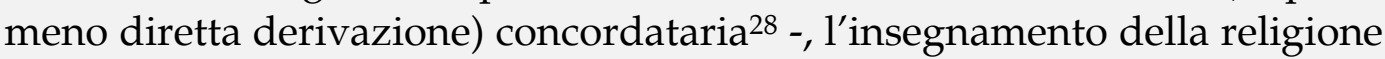
veniva sempre affidato tramite incarico annuale. Vigendo il Concordato del 1929, l'art. 5, primo comma, della legge n. 824 del 1930 aveva previsto, appunto, che l'insegnamento è affidato per incarico (senza concorso, dunque) "a persone scelte all'inizio dell'anno scolastico dal capo dell'istituto, inteso l'Ordinario diocesano".

Dopo l'Accordo del 18 febbraio 1984 di modificazioni del Concordato lateranense, il punto 5 del coevo Protocollo addizionale si è limitato a prevedere che, nel caso degli insegnanti così detti "specialisti", essi devono essere riconosciuti idonei dall'autorità ecclesiastica e sono "nominati, d'intesa con essa, dall'autorità scolastica". Sarà il Testo Unico in materia di istruzione ${ }^{29}$ a prevedere espressamente che per l'insegnamento della religione cattolica "il capo di istituto conferisce incarichi annuali d'intesa con l'ordinario diocesano" secondo le disposizioni concordate in materia tra Stato e Chiesa (art. 309, secondo comma), le quali, però, non contengono alcuna prescrizione riguardo al termine annuale di durata della nomina degli insegnanti di religione. Continuava a operare, inoltre, il loro possibile inquadramento come incaricati annuali "stabilizzati", in quanto alla scadenza annuale interveniva la conferma automatica nell'insegnamento, permanendo i requisiti previsti dalla legge, ossia la disponibilità del posto, l'idoneità concessa dall'Ordinario diocesano e, ancora, il non raggiungimento del limite massimo di età.

Su queste norme si è pronunziata la Corte costituzionale ${ }^{30}$ - all'esito di un giudizio che aveva visto sia la Presidenza del Consiglio dei ministri

${ }^{28}$ F. MARGIOTTA BROGLIO, Lo stato degli insegnanti di religione nell'ordinamento statuale, in Riv. giur. scuola, 1963, p. 770 ss. (citato a p. 779).

29 Decreto legislativo 16 aprile 1994, n. 297, Approvazione del testo unico delle disposizioni legislative vigenti in materia di istruzione, relative alle scuole di ogni ordine e grado.

30 Corte cost., sent. 13-22 ottobre 1999, n. 390, in Giur. cost., 1999, p. 3019 ss. Sulla pronunzia cfr. P. CAVANA, Osservazioni sullo stato giuridico dei docenti di religione, in Dir. fam. pers., 2000, p. 545 ss.; L. CIABATTINI, Insegnamento della religione cattolica e durata annuale dell'incarico, in Giur. cost., 2000, n. 1, p. 536 ss.; F. FRANCESCHI, Gli insegnanti di religione tra presente e futuro: brevi note a margine di una recente sentenza della Corte costituzionale, in Dir. eccl., 2000, II, p. 191 ss.; A. GUAZZAROTTI, L'insostenibile precarietà dell'insegnante di religione, in Giur. cost., 1999, n. 5, p. 3031 ss.; V. PALOMBO, L'insegnante di religione, il principio di uguaglianza e il diritto al lavoro, in Dir. eccl., 2000, II, p. 210 ss. 
sia i rappresentanti di parte confessionale insistere per il mantenimento inalterato dello status quo - senza ravvisare alcun contrasto con le norme di cui agli artt. 3, 4, 35 e 97 della Carta fondamentale. Il passaggio della decisione di più rilevante interesse non brilla, tuttavia, per chiarezza, limitandosi in esso la Corte ad affermare che la scelta dell'incarico (annuale) quale strumento di provvista degli insegnanti di religione non si manifesta "arbitraria o palesemente irragionevole, anche in relazione alle peculiarità di questo insegnamento" 31 .

Quale espressione di una linea tendente ad assimilare il più possibile la posizione degli insegnanti a tempo determinato a quella degli insegnanti di ruolo, in tema di progressione economica della carriera, l'art. 53, sesto comma, della legge 11 luglio 1980, n. 312, aveva intanto previsto che per i docenti di religione, dopo quattro anni di insegnamento, valessero le classi di stipendio corrispondenti all'ottanta per cento di quelle attribuite ai docenti laureati di ruolo, con l'obbligatorietà di costituzione e accettazione di posto orario con trattamento cattedra.

La legge n. 186 del $2003^{32}$ inaugura una fase nuova istituendo due ruoli regionali per gli insegnanti di religione "specialisti" (distinti in base al ciclo scolastico) articolati per ambiti territoriali corrispondenti alle diocesi (art. 1) $)^{33}$ e introducendo così, per la prima volta nel nostro

31 Corte cost., sent. 13-22 ottobre 1999, cit., punto 6.1 del Considerato in diritto.

32 Norme sullo stato giuridico degli insegnanti di religione cattolica degli istituti e delle scuole di ogni ordine e grado. Sulla riforma introdotta dalla legge, cfr., tra gli altri, A. BETTETINI, Lo status giuridico degli insegnanti di religione cattolica, in AA. VV., Insegnamenti e insegnanti di religione nella scuola pubblica italiana, a cura di A. MANTINEO, D. BilOtTI, S. MONTESANO, Giuffrè, Milano, 2014, p. 167 ss.; P. CAVANA, La riforma dello stato giuridico dei docenti di religione (legge n. 186/2003), in Dir. fam. pers., 2005, II, p. 1314 ss.; M. GATTAPONI, Insegnanti di religione: dalla precarietà alla immissione in ruolo. Primi nodi al vaglio della Corte costituzionale, in Quad. dir. pol. eccl., 3/2006, p. 785 ss.; A. GIANNI, La legge sul ruolo degli insegnanti di religione cattolica, in Quad. dir. pol. eccl., 2/2004, p. 381 ss.; M. MADONNA, Lo status giuridico degli insegnanti di religione cattolica tra diritto della Chiesa e ordinamento dello Stato, Libellula Edizioni, Tricase (Le), 2018; V. PACILLO, Contributo allo studio del diritto di libertà religiosa nel rapporto di lavoro subordinato, Giuffrè, Milano, 2003, p. 342 ss.; S.E. PIZZORNO, Il nuovo stato giuridico degli insegnanti di religione cattolica, in Nuova giur. civ. comm., 2004, II, n. 1, p. 196 ss.; V. PRIMERANO, Lo stato giuridico degli insegnanti di religione cattolica dopo la l. 186/2003, in Riv. giur. scuola, 2004, p. 109 ss.; A. TALAMANCA, Lo stato giuridico degli insegnanti di religione: bilanciamento tra impegni bilaterali ed equiparazione giuridica, in AA. VV., Diritto ecclesiastico e Corte costituzionale, a cura di R. BOTTA, Edizioni Scientifiche Italiane, Napoli, 2006, p. 323 ss.

33 Le diocesi rappresentano, infatti, "le circoscrizioni canoniche nell'ambito delle quali si realizzano concretamente le condizioni per l'affidamento dell'incarico di insegnamento (rilascio dell'idoneità da parte dell'Ordinario diocesano) e l'assegnazione della sede al 
ordinamento, la figura dell'insegnante di religione specialista a tempo indeterminato.

La riforma dovrebbe riflettere la veste nuova con cui, dopo l'Accordo di modifica del Concordato del 1929, lo stesso insegnamento di carattere confessionale è ammesso all'interno della scuola pubblica: un insegnamento legato ai "caratteri professionali, di preparazione culturale e di autonomia didattica", comuni agli altri insegnamenti, e che "hanno il loro principale strumento di garanzia nella stabilità del rapporto di lavoro" 34 .

Per quel che maggiormente interessa in questa sede, è previsto che la consistenza della dotazione organica degli insegnanti di religione cattolica venga determinata, prima al livello centrale e poi al livello regionale, nella misura del 70 per cento dei posti d'insegnamento complessivamente funzionanti (art. 2). Ne deriva "la sopravvivenza di una quota di docenti non di ruolo, che verranno assunti con contratto a tempo determinato" 35 a cui, come accadeva in passato per tutti gli insegnanti della categoria, non si applicheranno le norme di stato giuridico e il trattamento economico previsti dal testo unico delle disposizioni legislative vigenti in materia di istruzione ${ }^{36}$. Come è stato scritto, "[i]n sostanza costoro permangono nel regime di precarietà che ha contraddistinto lo status degli insegnanti di religione fino alla novella del 2003 "37, rendendo "più acuta la [loro] condizione di minorità" rispetto ai

singolo docente (l'intesa con l'Ordinario diocesano)": P. CAVANA, La riforma dello stato giuridico, cit., p. 1323.

${ }^{34}$ P. CAVANA, La riforma dello stato giuridico, cit., p. 1321. Condivide il postulato posto alla base di questa impostazione (per negarne, tuttavia, in radice l'applicabilità all'insegnante di religione), A. GUAZZAROTTI, La condizione degli insegnanti di religione e la "foglia di fico" della laicità dello Stato, in Forum di Quaderni cost., 9 giugno 2002, p. 2, secondo cui "[a]lla luce della tutela della libertà religiosa "positiva" di genitori e alunni, è del tutto coerente che prevalga la confessionalità, e con essa la precarietà, di tali docenti, anziché la loro stabilità e indipendenza, perché queste si legano piuttosto alla funzione dell'insegnante ordinario» (corsivi presenti nell'originale).

${ }^{35}$ N. FIORITA, Scuola pubblica e religioni, Libellula Edizioni, Tricase (Le), 2012, p. 166.

${ }^{36}$ Cfr. art. 2, decimo comma0, legge n. 186 del 2003: "Per tutti i posti non coperti da insegnanti con contratto di lavoro a tempo indeterminato, si provvede mediante contratti di lavoro a tempo determinato stipulati dai dirigenti scolastici, su indicazione del dirigente regionale, $\mathrm{d}$ 'intesa con l'ordinario diocesano competente per territorio".

37 P. CONSORTI, Sul nuovo stato giuridico degli insegnanti di religione cattolica, con particolare riferimento alla loro mobilità, in Stato, Chiese e pluralismo confessionale, cit., giugno 2009 , p. 3. 
colleghi di ruolo ${ }^{38}$.

Particolare attenzione ai nostri fini merita anche la disciplina delle diverse tipologie di mobilità previste per gli insegnanti di religione.

La novità più significativa introdotta a questo riguardo dalla legge n. 186 del 2003 riguarda proprio le due situazioni che potrebbero giustificare una speciale flessibilità o elasticità nel rapporto di lavoro che lega l'insegnante alla scuola, ossia quella conseguente alla revoca (sempre possibile) dell'idoneità rilasciata dall'Ordinario diocesano e quella della collocazione in quota soprannumeraria conseguente a una contrazione dei posti disponibili anche (ma non solo) per effetto delle scelte manifestate dagli studenti circa la frequenza dell'insegnamento.

In questi casi è previsto che l'insegnante di ruolo non debba subire la risoluzione del rapporto di lavoro, potendo fruire - sulla base di una scelta operata dal legislatore che ha suscitato in taluno "forti perplessità"39 - della mobilità professionale nel comparto del personale della scuola, con le modalità previste dalle disposizioni vigenti (subordinatamente al possesso dei requisiti prescritti per l'insegnamento richiesto, ossia l'abilitazione all'altro insegnamento), e avendo, altresì, titolo a partecipare alle procedure di diversa utilizzazione nell'ambito del pubblico impiego e

38 N. FIORITA, Scuola pubblica e religioni, cit., p. 180. Non si è, tuttavia, mancato di osservare che in tal modo si è assicurato "quel margine di elasticità necessario per conciliare le esigenze di stabilità dell'impiego per i posti in ruolo con quelle insite in un insegnamento rimesso ogni anno alla libera scelta delle famiglie e degli studenti e la cui titolarità è condizionata al continuativo possesso da parte del docente dell'idoneità rilasciata dall'autorità ecclesiastica": P. CAVANA, La riforma dello stato giuridico, cit., p. 1327.

39 Cfr. N. FIORITA, Scuola pubblica e religioni, cit., p. 171, il quale osserva che «l'esclusione di qualunque espressa e specifica modalità di verifica di natura concorsuale sulla "ulteriore" professionalità dell'insegnante di religione comporta l'insorgere di forti perplessità circa l'adeguato contemperamento degli interessi coinvolti e il rispetto dei principi costituzionali in gioco», dal momento che "altri insegnanti potrebbero [...] in forza della tutela accordata ad una specifica categoria, assistere alla compressione delle proprie possibilità di inserimento stabile nel mondo della scuola". Cfr. pure A. BETTETINI, Lo status giuridico, cit., p. 184, che evoca "un pregiudizio per la posizione di altri insegnanti" e una possibile lesione delle "legittime aspettative di altro personale pubblico"; S.E. PIZZORNO, Il nuovo stato giuridico, cit., p. 200; secondo A. GUAZZAROTTI, La condizione degli insegnanti di religione, cit., p. 3, "anche se la regola della mobilità fruibile ad libitum appare irragionevole", poiché "l'introduzione surrettizia di un canale privilegiato e confessionale di impiegati pubblici è assolutamente contraria al principio di non discriminazione per motivi religiosi", "una norma di "garanzia" degli insegnanti rispetto al venir meno dell'idoneità canonica sembra necessaria» (corsivo presente nell'originale). 
di mobilità collettiva previste dall'art. 33 del decreto legislativo n. 165 del 2001 (art. 4).

E tuttavia, come è stato osservato,

"[l]a possibilità che la diminuzione degli studenti che si avvalgono dell'ora di religione possa incidere sulla dotazione organica della scuola è in realtà abbastanza remota, stante il divieto di cui all'art. 2 della circolare ministeriale n. 368/1985, di tener conto di tale scelta nella composizione delle classi. In sostanza, l'impossibilità di procedere all'accorpamento degli studenti avvalentesi comporta che l'insegnamento dovrebbe continuare ad essere impartito anche nell'ipotesi che solo un alunno decidesse di frequentare il corso" 40 .

Resterebbe, comunque sia, da considerare il caso in cui tutti gli studenti della classe decidano di non avvalersi dell'insegnamento e quello dell'insegnante che veda concretizzarsi il pericolo, per lui sempre incombente, della revoca dell'idoneità da parte dell'Ordinario diocesano.

\section{4 - La vertenza riguardante gli insegnanti di religione cattolica e le questioni pregiudiziali sottoposte alla Corte di giustizia}

Un gruppo di insegnanti di religione cattolica, impiegati da diversi anni (più di tre), mediante la successione di contratti a tempo determinato, presso istituti di istruzione pubblica, convengono davanti al Tribunale di Napoli il Ministero dell'Istruzione, dell'Università e della Ricerca e l'Ufficio scolastico regionale per la Campania, chiedendo la conversione del loro contratto di lavoro a tempo determinato in un contratto di lavoro a tempo indeterminato $\mathrm{o}$, in subordine, il risarcimento del danno subìto, a causa del trattamento discriminatorio di cui sarebbero state vittime rispetto ai docenti di altre materie.

Il giudice del rinvio reputa irricevibili le richieste degli insegnanti. Non ritiene di potere accogliere la domanda di conversione del rapporto, essendo quello che lega l'insegnante di religione all'istituto scolastico un rapporto di pubblico impiego, per il quale, come si è visto più sopra, non trova applicazione questo meccanismo sanzionatorio previsto in caso di successione dei contratti a termine che superi il termine di durata massima; esclude la possibilità di riconoscere un risarcimento del danno,

40 N. FIORITA, Scuola pubblica e religioni, cit., p. 171, nt. 409. Sul punto cfr. pure A. GUAZZAROTTI, La condizione degli insegnanti di religione, cit., p. 2, che, a proposito di temute massicce riduzioni dei posti di insegnamento, parla di "ipotesi altamente improbabile", anche in ragione della "assoluta assenza di "concorrenza" con l'i.r.c.». 
in quanto la normativa sul contratto di lavoro a tempo determinato che potrebbe costituire la base legale di un tale diritto non trova, comunque sia, applicazione, come pure si è visto più sopra, nell'ambito delle supplenze del personale insegnante; emerge poi una palese diversità di trattamento tra gli insegnanti di religione e i colleghi di altre materie, dal momento che solo per questi ultimi vale il meccanismo dell'immissione in ruolo previsto dall'art. 399 del già citato decreto legislativo n. 297 del 1994, o quello disciplinato dalla legge 13 luglio 2015, n. 10741, intervenuta per consentire una generale regolarizzazione del personale docente precario.

I dubbi di conformità di un tale regime rispetto al diritto dell'Unione europea concernono pertanto l'assenza di un qualsiasi meccanismo che sanzioni una ingiustificata (e quindi abusiva) successione di contratti di lavoro a tempo determinato stipulati dagli organi scolastici con gli insegnanti di religione.

Invero, per quanto riguarda la suddetta impossibilità di ottenere la conversione del rapporto, la posizione degli insegnanti di religione non è diversa da quella dei colleghi (supplenti) di altre materie (salvo a volere considerare il necessario possesso dell'idoneità rilasciata dall'ordinario diocesano quale elemento atto a evidenziare "ulteriormente la precarietà del rapporto di lavoro di un insegnante di religione cattolica") ${ }^{42}$; tuttavia, il giudice del rinvio dubita della compatibilità con il diritto dell’Unione europea di tale situazione, mancando qualsiasi misura, nell'ordinamento giuridico interno, atta a sanzionare gli abusi derivanti dalla successione di contratti a termine.

La Corte di giustizia è stata, dunque, chiamata a chiarire:

a) anzitutto, se sussista una discriminazione per motivi di religione ai danni degli insegnanti di religione ai sensi dell'art. 21 della Carta dei diritti fondamentali dell'Unione europea e della direttiva 2000/78/CE che stabilisce un quadro generale in materia di occupazione e di condizioni del lavoro o se, invece, il necessario possesso dell'idoneità di cui sopra possa essere considerato come fattore giustificativo dell'assenza di qualsiasi meccanismo sanzionatorio legato alla successione di contratti a termine;

41 Riforma del sistema nazionale di istruzione e formazione e delega per il riordino delle disposizioni legislative vigenti.

42 Corte di giustizia U.E., 13 gennaio 2022, cit., par. 37 «Infine, il giudice del rinvio ricorda che l'insegnamento della religione cattolica è subordinato al rilascio all'insegnante, da parte dell'ordinario diocesano, di un "riconoscimento di idoneità" [...], che non sia stato revocato. La revoca dell'idoneità costituirebbe quindi un motivo valido di licenziamento, aspetto che comproverebbe ulteriormente la precarietà del rapporto di lavoro di un insegnante di religione cattolica». 
b) nel caso di accertata ricorrenza della discriminazione, se il giudice di merito possa procedere alla costituzione di un rapporto di lavoro a tempo indeterminato con l'Amministrazione convenuta;

c) se, nel caso di ritenuta applicabilità in astratto, alla specifica materia controversa, del meccanismo sanzionatorio di una successione avente eccessiva durata di contratti a tempo determinato, non possa costituire una valida ragione obiettiva [così come individuata dalla clausola 5, punto 1, lettera $a$ ), dell'Accordo quadro] tale da giustificare la sua non operatività in concreto, la circostanza che l'insegnante di religione, a differenza degli altri insegnanti, deve essere in possesso dell'idoneità rilasciata e non revocata dall'ordinario diocesano (salvo a considerare discriminatorio il regime giuridico che ne consegue), con

d) eventuale disapplicazione delle norme interne che impediscono la conversione automatica del contratto di lavoro.

\section{5 - L'eventuale incidenza dell'impegno dell'Unione a salvaguardare lo status previsto per le confessioni religiose dal diritto nazionale (art. 17 TFUE)}

Capita con una certa frequenza che nelle controversie concernenti la materia ecclesiastica portate davanti alla Corte di giustizia si chiami in causa il principio sancito dall'art. 17 TFUE ${ }^{43}$.

${ }_{43} \mathrm{Su}$ tale disposizione, cfr. AA. VV., Le confessioni religiose nel diritto dell'Unione europea, a cura di L. DE GREGORIO, il Mulino, Bologna, 2012; D. DURISOTTO, Istituzioni europee e libertà religiosa. Cedu e Ue tra processi di integrazione europea e rispetto delle specificità nazionali, Edizioni Scientifiche Italiane, Napoli, 2016, p. 301 ss.; A. LICASTRO, Unione europea e «status» delle confessioni religiose tra tutela dei diritti umani fondamentali e salvaguardia delle identità costituzionali, Giuffrè, Milano, 2014; ID., L'influenza della Carta di Nizza sui sistemi nazionali europei di disciplina del fenomeno religioso: verso un diritto ecclesiastico dell'Unione?, in AA. VV., La Carta dei diritti dell'Unione Europea e le altre Carte (ascendenze culturali e mutue implicazioni), a cura di L. D'ANDREA, G. MOSCHELLA, A. RUGGERI, A. SAITTA, Giappichelli, Torino, 2016, p. 325 ss.; M. LUGATO, L'Unione europea e le Chiese: l'art. 17 TFUE nella prospettiva del principio di attribuzione, del rispetto delle identità nazionali e della libertà religiosa, in Quad. dir. pol. eccl., n. 2/2014, p. 305 ss.; V. MARANO, L'art. 17 TFUE e il ruolo delle Chiese in Europa, in Ephemerides iuris canonici, 2015, n. 1, p. 21 ss.; F. MARGIOTTA BROGLIO, M. ORLANDI, Articolo 17 del Trattato sul funzionamento dell'Unione europea, in AA. VV., Trattati dell'Unione europea, 2a ed., a cura di A. TIZZANO, Giuffrè, Milano, 2014, p. 454 ss.; S. MONTESANO, Brevi riflessioni sull'art. 17 TFUE e sul progetto di Direttiva del Consiglio recante disposizioni in materia di divieto di discriminazione, in Stato, Chiese e pluralismo confessionale, cit., n. 18 del 2015, p. 1 ss.; M. VENTURA, L'articolo 17 TFUE come fondamento del diritto e della politica ecclesiastica dell'Unione europea, in Quad. 
Disposizione frutto, come si ricorderà, di una gestazione e di un parto molto travagliati, il cui contenuto è tutt'altro che difficile da armonizzare col principio del primato e dell'applicazione uniforme del diritto dell'Unione (essendo espressione diretta di quel diritto, al più elevato livello delle fonti dell'ordinamento europeo); essa è, tuttavia, oggetto di letture dottrinali e giurisprudenziali "minimaliste", destinate a svuotarla quasi del tutto di un qualsiasi contenuto capace di darle un senso ragionevole e non banalmente ovvio, oltreché privo di qualsiasi pratica rilevanza.

A premere, a suo tempo, per l'inserimento nei trattati comunitari di una norma di salvaguardia del regime giuridico nazionale dei culti, come pure è noto, erano state le chiese più tradizionali ${ }^{44}$. Questo rende apparentemente abbastanza singolare che a invocarla, confidando che essa potesse servire a garantire l'intangibilità da parte del diritto dell'Unione dell'assetto normativo nazionale in materia di rapporto di lavoro degli insegnanti di religione, sia stata, anche questa volta ${ }^{45}$, la parte statale, ossia il Ministero convenuto. Tutto questo, tuttavia, a ben vedere, riflette un assetto sistematico complessivo ben preciso. Non bisogna poi dimenticare che ogni controversia, in fondo, risponde a una sua propria logica e che l'estrema complessità dei moderni ordinamenti giuridici ben si presta a offrire risorse anche inaspettate da utilizzare sulla base delle convenienze del caso e del momento.

A me pare che le argomentazioni sviluppate dalla Corte, in questa parte della pronunzia, siano corrette e possano contribuire a chiarire, in termini parzialmente nuovi rispetto ai primi precedenti, anche la portata che i giudici di Lussemburgo attribuiscono al principio sancito nell'art. 17 TFUE.

In fondo, l'approccio adottato dal Governo italiano, secondo cui dovrebbe entrare in gioco la disposizione in questione qualora le questioni sottoposte alla Corte riguardino "i rapporti tra l'ordinamento giuridico della Repubblica italiana e [...] l'ordinamento giuridico della Chiesa cattolica, rapporti che rientrano esclusivamente nell'ambito del diritto

dir. pol. eccl., n. 2/2014, p. 293 ss.; ID., Dynamic Law and Religion in Europe. Acknowledging Change. Choosing Change, European University Institute Working Paper, Religio West Project, 2013.

${ }^{44}$ A. LICASTRO, Unione europea e«status», cit., p. 123.

45 Nel caso deciso dalla sentenza della Grande Sezione 22 gennaio 2019, causa C-193/17, Cresco Investigation GmbH c. Achatz, a invocarla era stato il Governo polacco, intervenuto nel processo a fianco del Governo austriaco, convenuto in giudizio. 
interno" 46 , è pienamente corretto ed è sostanzialmente accettato dagli stessi Giudici europei. I quali, però, altrettanto correttamente, pur ammettendo che il principio di cui all'art. 17 TFUE interviene, appunto, sulla scia di quanto si era affermato in Cresco Investigation $\mathrm{GmbH}$ c. Achatz, nel caso in cui le disposizioni nazionali siano "dirette a organizzare i rapporti tra uno Stato membro e le chiese", sottolineano che nel caso concreto questo non accade, dal momento che quelle disposizioni, di cui al procedimento principale, riguardano piuttosto "le condizioni di lavoro degli insegnanti di religione cattolica presso gli istituti pubblici" 47 , senza incidere, in alcun modo, né sul necessario possesso dell'idoneità all'insegnamento rilasciata dall'ordinario diocesano, né sul carattere facoltativo della materia: questioni, sicuramente, non del tutto indipendenti da quella, rimessa alla pronunzia della Corte, della durata del rapporto di lavoro dell'insegnante (e della possibile conversione del contratto a tempo determinato in contratto a tempo indeterminato), ma non così inscindibilmente connesse, si potrebbe dire, da comportare una incompetenza della Corte a pronunziarsi sulla questione sottopostale. $\mathrm{Su}$ questo specifico aspetto si era del resto pronunciata anche la Corte costituzionale italiana, escludendo che la materia riguardante la nomina a termine dell'insegnante di religione dovesse farsi rientrare nella disciplina concordata tra Stato e Chiesa ${ }^{48}$.

La novità, emergente dalla pronunzia, rispetto ai primi precedenti, a proposito della portata da riconoscere all'art. 17 TFUE, sembra essere

${ }^{46}$ Corte di giustizia U.E., 13 gennaio 2022, cit., par. 39.

${ }^{47}$ Corte di giustizia U.E., 13 gennaio 2022, cit., par. 51.

${ }^{48}$ Aveva precisato al riguardo la Corte costituzionale che la previsione normativa che disciplina il conferimento dell'incarico annuale all'insegnante di religione "sia pure adottata nel contesto dell'impegno concordatario di assicurare l'insegnamento della religione cattolica nelle scuole pubbliche, riguarda un aspetto dello stato giuridico degli insegnanti di religione, la cui disciplina è rimessa alla competenza del legislatore statale, il quale, nel rispetto degli impegni pattizi, può discrezionalmente stabilire una regolamentazione coerente con il sistema scolastico e adeguata alle particolari caratteristiche di questo insegnamento"; e poco più avanti che la "questione di legittimità costituzionale, pur muovendo in questo contesto, non riguarda tuttavia, come si è già precisato, la normativa di derivazione bilaterale, bensì la disciplina statale che, nell'ambito della discrezionalità propria della legislazione scolastica, regolamenta lo stato giuridico degli insegnanti di religione prevedendo la loro nomina con efficacia annuale" (sent. 13-22 ottobre 1999, cit., punto 2 e punto 4 del Considerato in diritto). In dottrina, sottolinea, fra gli altri, che l'impegno politico cui ha dato seguito l'approvazione della legge sul nuovo stato giuridico degli insegnanti di religione rientra "in pieno nelle competenze proprie ed esclusive dello Stato", P. CAVANA, La riforma dello stato giuridico, cit., p. 1315. 
quella che la "neutralità dell'Unione nei confronti dell'organizzazione da parte degli Stati membri, dei loro rapporti con le Chiese e le associazioni o comunità religiose" 49 , in cui si era fin qui ritenuto che dovesse consistere la portata concreta da riconoscere a quella disposizione, è ora intesa, così come in Cresco Investigation $\mathrm{GmbH}^{50}$, come effettivo impegno a salvaguardare la disciplina di quei rapporti esistente al livello nazionale (del resto la norma parla chiaramente proprio di impegno dell'Unione a "rispettare" e a "non pregiudicare" lo status goduto in ambito statale dalle confessioni religiose, e non di impegno a mantenere una posizione di "neutralità" rispetto a esso). Se non altro, l'indicazione offerta dalla Corte serve a chiarire meglio un concetto ambiguo (quello di "neutralità" nell'organizzazione dei rapporti tra Stato e confessioni), suscettibile di diverse letture.

In Cresco Investigation $\mathrm{GmbH}$ è piuttosto l'applicazione concreta di quella regola che appare poco convincente, in quanto le norme che disciplinano il godimento dei giorni festivi in concomitanza con particolari ricorrenze religiose, come quelle di cui si trattava nel procedimento nazionale davanti al giudice del rinvio, sono tipicamente afferenti alla materia dei rapporti tra lo Stato e le confessioni religiose.

Non può indurre a ritenere il contrario la circostanza che la disciplina contestata del giorno festivo aggiuntivo (Venerdì Santo) riconosciuto in Austria ai fedeli di determinate confessioni religiose (membri delle Chiese evangeliche di confessione augustana e di confessione elvetica, della Chiesa vetero-cattolica e della Chiesa evangelica metodista) fosse dettata da una normativa generale riguardante i periodi di riposo dei lavoratori (Arbeitsruhegesetz 144/1983) e non dalle normative riguardanti i "rapporti esterni" delle medesime confessioni ${ }^{51}$. È tutto da dimostrare che "lo status di cui le chiese e le associazioni o comunità religiose godono negli Stati membri in virtù del diritto nazionale", di cui parla l'art. 17 TFUE, debba in qualche modo dipendere da normative speciali volte a disciplinare direttamente la materia ecclesiastica e non anche da norme di diritto comune che disciplinano materie chiaramente

${ }^{49}$ Corte di giustizia U.E., Grande Sezione, 17 aprile 2018, causa C-414/16, Egenberger c. Evangelisches Werk für Diakonie und Entwicklung $\mathrm{eV}$, par. 58; Id., 11 settembre 2018, causa C-68/17, IR c. JQ, par. 48; Id., 22 gennaio 2019, cit., par. 33.

50 Corte di giustizia U.E.., 22 gennaio 2019, cit., par. 33, dove si era affermato che "le disposizioni nazionali di cui trattasi nel procedimento principale non sono dirette a organizzare i rapporti tra uno Stato membro e le chiese".

$51 \mathrm{Su}$ queste ultime, cfr. A. LICASTRO, Il diritto statale delle religioni nei Paesi dell'Unione europea. Lineamenti di comparazione, 2a ed., Giuffrè, Milano, 2017, p. 44 s. 
incidenti su interessi delle confessioni religiose ${ }^{52}$. Proprio una considerazione meramente formale di quel tipo sembra avere, invece, indotto la Corte di giustizia a ritenere che

"le disposizioni nazionali di cui trattasi nel procedimento principale non sono dirette a organizzare i rapporti tra uno Stato membro e le chiese, ma mirano unicamente a concedere ai lavoratori, membri di talune chiese, un giorno festivo supplementare che coincide con una festa religiosa importante per tali chiese ${ }^{\prime \prime 53}$.

Questo tipo di approccio della Corte, che tiene conto del significato della festa religiosa per alcune chiese (e non per altre), pare difficilmente conciliabile con l'asserto secondo cui la legislazione austriaca avrebbe inteso semplicemente avvantaggiare dal punto di vista economico i fedeli appartenenti a determinate confessioni ${ }^{54}$.

Che quella disciplina crei una disparità di trattamento tra lavoratori per motivi religiosi è, comunque sia, altrettanto evidente, pur potendosi prefigurare diverse soluzioni di "accomodamento", spesso necessarie quando si tratta di governare la convivenza tra diverse "identità" religiose e, più genericamente, culturali, tipiche delle moderne società pluralistiche. La stessa soluzione individuata dalla Corte si ispira a questa logica e appare accettabile al netto, però, dell'aggravio in termini di costi per il datore di lavoro ${ }^{55}$.

52 Cfr. A. LICASTRO, Unione europea e«status», cit., p. 198: «il "diritto nazionale" richiamato dall'art. 17 TFUE è proprio il settore dell'ordinamento degli Stati membri dell'Unione concernente la disciplina giuridica del fenomeno religioso. Un settore [...] non necessariamente costituente un corpus organico e "speciale" di regole e principi - per tipologia delle fonti giuridiche di produzione o per i contenuti delle norme costitutive (soltanto in alcuni casi rivestite di carattere tipicamente derogatorio) - ma circoscrivibile sulla base del suo particolare (e, in questo senso, "specifico") campo materiale di applicazione».

53 Corte di giustizia U.E.., 22 gennaio 2019, cit., par. 33.

${ }^{54} \mathrm{Cfr}$., in questo senso, S. BALDETTI, Festività religiose e normativa discriminatoria alla prova della Corte di Giustizia dell'Unione Europea, in Lavoro Diritti Europa, n. 2, 2019, p. 5, secondo cui "[q]uello che [...] realizza la normativa austriaca non è tanto un riconoscimento di una specificità confessionale rispetto al considerare o meno come festivo un particolare giorno dell'anno, quanto conferire solo ad alcune categorie di lavoratori un vantaggio di tipo economico rispetto agli altri, in ragione della propria appartenenza confessionale".

55 I giudici hanno, infatti, stabilito che "finché lo Stato membro interessato non abbia modificato, al fine di ripristinare la parità di trattamento, la propria normativa che concede il diritto ad un giorno festivo il Venerdì santo solo ai lavoratori membri di talune chiese cristiane, un datore di lavoro privato soggetto a detta normativa ha l'obbligo di accordare anche agli altri suoi lavoratori il diritto a un giorno festivo il Venerdì santo, 
Un diverso giudizio penso debba darsi del tipo di applicazione del principio ricavabile dall'art. 17 TFUE fatto dalla pronunzia in esame, decisamente più convincente nel ritenere esclusa ogni incidenza sulla materia dei rapporti tra Stato e Chiesa della disciplina concernente la questione controversa.

In ogni caso, si deve ribadire che non è semplicemente la neutralità dell'Unione in materia di relazioni con le chiese che viene in gioco con l'art. 17 TFUE, ma c'è dell'altro, e cioè l'impegno a rispettare la disciplina concretamente esistente di quei rapporti. Fuori da tale ambito, c'è tutto lo spazio per constatare, senza preclusioni imposte da quell'impegno, la ricorrenza di una eventuale discriminazione ai danni degli insegnanti di religione ai sensi della direttiva 2000/78/CE. Così come non esistono margini per escludere dal campo di applicazione dell'Accordo quadro sopra richiamato eventuali sanzioni in caso di abuso nell'utilizzo di una successione di contratti a tempo determinato nei confronti degli insegnanti di religione cattolica.

\section{6 - La tutela antidiscriminatoria degli insegnanti di religione: a) l'assenza di una discriminazione per motivi di religione rispetto alla posizione degli altri supplenti della scuola pubblica}

Una volta sgomberato il terreno da possibili preclusioni o influenze derivanti dall'art. 17 TFUE, il diritto dell'Unione europea ha modo di imporsi e spiegare piena efficacia su quella che presenta tutte le caratteristiche di una controversia riguardante la disciplina applicabile a un rapporto di lavoro, pur non privo di alcune peculiarità di non trascurabile rilievo e importanza.

La Corte deve, anzitutto, rispondere alla questione, posta dal giudice del rinvio, riguardante la possibile ricorrenza di una discriminazione diretta ai danni dell'insegnante di religione (ai sensi dell'art. 21 della Carta dei diritti fondamentali e ai sensi della direttiva 2000/78/CE e, dunque, per motivi di religione, gli unici, tra quelli contemplati dalla stessa ${ }^{56}$, teoricamente ricollegabili alla fattispecie), e qui

purché questi ultimi abbiano chiesto in anticipo a detto datore di lavoro di non dover lavorare quel giorno e, di conseguenza, di riconoscere a tali lavoratori il diritto ad un'indennità per giorno festivo, quando detto datore di lavoro non abbia accolto siffatta richiesta" (Corte di giustizia U.E.., 22 gennaio 2019, cit., par. 89).

56 Ricordo che la direttiva 2000/78/CE contempla quali unici fattori di rischio "la religione o le convinzioni personali, gli handicap, l'età o le tendenze sessuali". 
essa ha gioco facile nel ritenere esclusa ogni possibile censura, da quel preciso punto di vista, della normativa nazionale.

Sia (come ritiene la Corte) o no la posizione dell'insegnante di religione assunto con contratto a tempo determinato effettivamente comparabile a quella dei colleghi di altre materie pure assunti a tempo determinato, la contestata diversità di trattamento non sarebbe determinata da "caratteristiche collegate con la religione" (professata o non professata, manifestata apertamente o posseduta nel foro interno, dal soggetto), ma riguarderebbe "soltanto la disciplina applicabile al rapporto di lavoro" 57.

Quella caratteristica incide sicuramente sulla fase dell'assunzione dell'insegnante, come anche sulla permanenza dello stesso rapporto con l'istituto di istruzione, sempre subordinata, come si sa, alla conservazione dell'idoneità riconosciuta dall'Ordinario diocesano. Ma è una caratteristica tutta intrinseca al rapporto di lavoro dell'insegnante di religione (non direttamente correlata alla religione del lavoratore) che può determinare l'assunzione con contratto a tempo determinato (così come per i colleghi assunti a tempo determinato per insegnare altre materie e diversamente dai colleghi assunti a tempo indeterminato), l'impossibilità di ottenerne la conversione in rapporto a tempo indeterminato (alla stessa stregua dell'insegnamento delle altre materie), o ancora l'impossibilità di accedere al meccanismo dell'immissione in ruolo previsto dall'art. 399 del decreto legislativo 16 aprile 1994, n. 297, o a quello disciplinato dalla legge 13 luglio 2015, n. 107 (a differenza dei colleghi delle altre materie). Argomentazioni, quelle dei giudici di Lussemburgo, tutto sommato persuasive, salvo doversi chiedere se ogni differenziazione nel regime del rapporto di lavoro dell'insegnante di religione sia o no conforme al canone della ragionevolezza: domanda a cui la Corte di giustizia non può rispondere, perché del tutto estranea dal campo applicativo proprio della direttiva 2000/78/CE e dall'ambito in cui essa spiega i suoi effetti ${ }^{58}$.

$\mathrm{Va}$ anche considerato che solo in parte appare come adeguato termine di comparazione della posizione dell'insegnante di religione

57 Corte di giustizia U.E., 13 gennaio 2022, cit., par. 65.

58 Infatti, "quando è investita di una questione pregiudiziale vertente sull'interpretazione del principio generale di non discriminazione in base alla religione, quale sancito dall'articolo 21 della Carta, nonché delle disposizioni della direttiva $2000 / 78$, le quali attuano tale articolo 21 e contribuiscono alla realizzazione degli obiettivi del medesimo, nel contesto di una controversia tra un singolo e un'amministrazione pubblica, la Corte esamina tale questione alla luce di tale direttiva" (Corte di giustizia U.E., 13 gennaio 2022, cit., par. 61). 
quella del "classico" supplente (che ricopre cioè delle supplenze temporanee, sull'organico così detto "di fatto", oppure brevi). In questi casi, come precisava la stessa normativa sui contratti di lavoro a tempo determinato (art. 10, comma 4-bis, del decreto legislativo n. 368 del 2001 , più sopra riprodotta), vengono in gioco ragioni (chiaramente oggettive) di sostituzione di personale, magari che ricopre a tempo indeterminato il posto, temporaneamente assente dal servizio, al fine di garantire la costante erogazione del servizio scolastico ed educativo; il che, invece, non accadeva mai in passato, e potrebbe oggi, a termini di legge, non accadere per la quota di dotazione organica del 30\%, nel caso dell'insegnante di religione, chiamato a ricoprire un posto già in partenza, per così dire, inserito nella disponibilità dei posti come a tempo determinato. Forse una maggiore similitudine si coglie con colui cui è affidata una supplenza annuale (sull'organico così detto "di diritto", ossia) su posto vacante e disponibile perché privo di titolare.

In ogni caso, l'esclusione della discriminazione diretta non implica che si debba tralasciare di verificare, come opportunamente sottolineato dalla Corte ${ }^{59}$, che possa ricorrere nella fattispecie una discriminazione indiretta, ipotizzando che la disposizione di legge con cui si equipara la condizione, nel settore dell'insegnamento pubblico, di tutti i docenti assunti a termine, sia solo apparentemente neutra dal punto di vista delle credenze religiose, in quanto causa di particolari effetti pregiudizievoli per chi professi la religione cattolica: pare, tuttavia, arduo immaginare (senza considerare le possibili giustificazioni di un trattamento differenziato fonte del particolare svantaggio) che la professione della fede cattolica possa, al contempo, costituire un fattore che penalizzi l'insegnante di religione e anche un fattore che lo avvantaggi, essendo condizione ineludibile per potere assumere l'insegnamento.

L'esclusione della discriminazione ai danni dell'insegnante di religione non è certo una buona notizia per i ricorrenti, perché li priva della possibilità di invocare un principio (il divieto di discriminazione per motivi di religione di cui all'art. 21 della Carta dei diritti fondamentali dell'Unione europea) "autosufficiente" e, quindi, immediatamente e direttamente applicabile anche nella controversia che li vedeva contrapposti al Ministero dell'Istruzione e all'Ufficio scolastico regionale ${ }^{60}$.

59 Corte di giustizia U.E., 13 gennaio 2022, cit., par. 66.

${ }^{60}$ Cfr. A. LICASTRO, Il regime giuridico delle organizzazioni confessionali di tendenza, tra garanzie costituzionali forti e interpretazioni omologanti (o abroganti?) della Corte di giustizia $U E$, in Quad. dir. pol. eccl., p. 863 ss. (in particolare p. 884 ss.). 


\section{7 - (segue) b) L'inapplicabilità della clausola 4 dell'Accordo quadro}

Indipendentemente dal modo in cui sono state formulate dal giudice di rinvio le questioni pregiudiziali, il vero punto da dirimere è se la situazione in cui versano gli insegnanti di religione sia o no compatibile con la direttiva 1999/70/CE e, quindi, con le clausole contenute nell'Accordo quadro che essa recepisce.

Bisogna, infatti, ricordare che la Corte di giustizia, "pur riconoscendo ampi margini di discrezionalità ai legislatori nazionali", ha sempre ribadito che gli stessi non possono "discrezionalmente escludere specifiche categorie di lavoratori dall'applicazione della disciplina"61. E la pronunzia in esame della Corte si mantiene perfettamente allineata a questo indirizzo ${ }^{62}$, pervenendo al risultato di ritenere pienamente applicabile anche agli insegnanti di religione la disciplina dell'Accordo quadro. Questo impone di ricostruire il significato e gli effetti che derivano dall'Accordo e, in particolare, dalla clausola 4 (così detta "clausola paritaria") e dalla successiva clausola 5 (così detta "clausola antiabusiva") ${ }^{63}$ richiamate dal giudice del rinvio.

Quanto alla prima, essa si occupa del principio di non discriminazione e al paragrafo 1 è così formulata:

${ }^{61}$ G. LUDOVICO, Contratto a tempo determinato, cit., p. 84, cui rinvio per l'indicazione dei precedenti e delle opportune referenze dottrinali (ivi, nt. 75). Sul campo di applicazione della direttiva, cfr. M. VICECONTE, L'ambito di applicazione della Direttiva 199/70/CE del Consiglio dell'Unione europea 28 giugno 1999 relativa all'accordo quadro CES, UNICE e CEEP sul lavoro a tempo determinato, in Lavoro e previdenza oggi, 2010, n. 6, pp. 635 ss.

${ }^{62}$ La Corte ricorda, infatti, che «dalla stessa formulazione della clausola 2, punto 1, dell'accordo quadro risulta che l'ambito d'applicazione di quest'ultimo è concepito in senso ampio, poiché riguarda in generale $\mathrm{i}$ "lavoratori a tempo determinato con un contratto di assunzione o un rapporto di lavoro disciplinato dalla legge, dai contratti collettivi o dalla prassi in vigore di ciascuno Stato membro". Inoltre, la definizione della nozione di "lavorator[i] a tempo determinato" ai sensi della clausola 3, punto 1, dell'accordo quadro include tutti i lavoratori, senza operare distinzioni basate sulla natura pubblica o privata del loro datore di lavoro" (par. 69). Pertanto "l'accordo quadro non esclude alcun settore particolare dal suo ambito di applicazione, esso si applica quindi anche al personale assunto nel settore dell'insegnamento impartito presso istituti pubblici" (par. 70). 10.

63 Per queste qualificazioni delle due clausole, cfr. M. AIMO, Il lavoro a termine, cit., p. 


\begin{abstract}
"Per quanto riguarda le condizioni di impiego, i lavoratori a tempo determinato non possono essere trattati in modo meno favorevole dei lavoratori a tempo indeterminato comparabili per il solo fatto di avere un contratto o rapporto di lavoro a tempo determinato, a meno che non sussistano ragioni oggettive".
\end{abstract}

È evidente che la clausola mette in comparazione i lavoratori a tempo determinato con i lavoratori a tempo indeterminato i quali versino in una situazione analoga, e lo fa al fine di impedire che l'apposizione del termine di durata si trasformi in uno strumento utilizzato da un datore di lavoro per privare alcuni lavoratori dei diritti spettanti ai lavoratori a tempo indeterminato. La clausola in questione non può quindi essere invocata per rendere possibile la conversione del contratto a tempo determinato, con cui viene assunta una particolare categoria di lavoratori, in rapporto a tempo indeterminato, lamentando una disparità di trattamento fra lavoratori a tempo determinato. Per comprendere il ragionamento della Corte, bisogna ricordare che essa dà per scontato che, a differenza di quanto risulta dal tenore della nostra legislazione nazionale, anche $\mathrm{i}$ supplenti annuali su posti vacanti e disponibili impegnati nell'insegnamento pubblico possono godere, a determinate condizioni, del diritto alla conversione del loro rapporto ${ }^{64} \mathrm{e}$, con ragionevole conseguenzialità, rispetto alla condizione di tali insegnanti, così ricostruita, la medesima Corte opera la comparazione della condizione in cui versano gli insegnanti di religione cattolica (che si assume non possano vantare quel diritto).

Resta, pertanto, escluso che il giudice nazionale possa disapplicare le norme che impediscono, nel caso degli insegnanti di religione cattolica, la conversione automatica di un contratto a tempo determinato in un contratto a tempo indeterminato applicando la clausola 4 dell'Accordo quadro.

64 Cfr. Corte di giustizia U.E., 13 gennaio 2022, cit., par. 74: "il fatto che taluni lavoratori a tempo determinato, come i ricorrenti nel procedimento principale, non possano beneficiare di una conversione del loro contratto di lavoro in contratto a tempo indeterminato, mentre altri lavoratori dell'insegnamento pubblico che insegnano altre materie e si trovano in una situazione comparabile potevano farlo, costituisce appunto una differenza di trattamento tra due categorie di lavoratori a tempo determinato" (mio il corsivo). 


\title{
8 - La prevenzione degli abusi della successione dei contratti a tempo determinato per gli insegnanti di religione: in particolare le "ragioni obiettive" che possono giustificare il rinnovo
}

La clausola 5 dell'Accordo quadro mira, invece, a imporre particolari misure di prevenzione degli abusi nella successione dei contratti a termine e può, quindi, dare appropriate indicazioni per la soluzione della specifica questione controversa. Il testo del paragrafo 1 della clausola è così formulato:

\begin{abstract}
"Per prevenire gli abusi derivanti dall'utilizzo di una successione di contratti o rapporti di lavoro a tempo determinato, gli Stati membri, previa consultazione delle parti sociali a norma delle leggi, dei contratti collettivi e della prassi nazionali, e/o le parti sociali stesse, dovranno introdurre, in assenza di norme equivalenti per la prevenzione degli abusi e in un modo che tenga conto delle esigenze di settori e/o categorie specifici di lavoratori, una o più misure relative a: $a$ ) ragioni obiettive per la giustificazione del rinnovo dei suddetti contratti o rapporti; $b$ ) la durata massima totale dei contratti o rapporti di lavoro a tempo determinato successivi; $c$ ) il numero dei rinnovi dei suddetti contratti o rapporti".
\end{abstract}

Come già in altre occasioni la Corte di giustizia aveva chiarito, tale clausola ha lo scopo di

"limitare il ripetuto ricorso ai contratti o ai rapporti di lavoro a tempo determinato, considerato come potenziale fonte di abuso a danno dei lavoratori, prevedendo un certo numero di disposizioni di tutela minima volte ad evitare la precarizzazione della situazione dei lavoratori dipendenti" ${ }^{65}$.

Tuttavia, gli Stati membri non sono vincolati ad adottare tutte le misure indicate dalla clausola (ragioni obiettive per la giustificazione del rinnovo, durata massima totale, numero massimo di rinnovi), in mancanza di norme equivalenti nel diritto interno; possono, invece, scegliere di fare ricorso anche a una sola delle misure indicate o a eventuali norme interne equivalenti. Sul versante delle sanzioni, agli Stati membri sono riservati margini di discrezionalità ancora più estesi, mancando, per esempio, qualsiasi obbligo di prevedere la trasformazione dei contratti di lavoro a

${ }^{65}$ Corte di giustizia U.E., Sez. VII, 3 giugno 2021, causa C-726/19, Instituto Madrileño de Investigación y Desarrollo Rural, Agrario y Alimentario c. JN, par. 26; Id., 11 febbraio 2021, causa C-760/18, M.V. e a. c. Organismos Topikis Aftodioikisis (OTA) «Dimos Agiou Nikolaou», par. 36; Id., sez. II, 19 marzo 2020, causa C-103/18 e C-429/18, Sánchez Ruiz, Fernández Álvarez e altri c. Comunidad de Madrid (Servicio Madrileño de Salud), par. 53. 
tempo determinato in contratti a tempo indeterminato, purché le misure previste offrano garanzie adeguate in termini di concreta efficacia in funzione del contrasto dei fenomeni abusivi che la direttiva persegue. Tutto questo vale anche per gli insegnanti di religione, in relazione ai quali non sarebbe tollerabile che l'ordinamento interno non prevedesse alcuna misura per prevenire e sanzionare eventuali abusi, pregiudicando l'obiettivo della clausola 5 dell'Accordo quadro ${ }^{66}$.

Stando all'assetto del nostro ordinamento, non è in vigore, per gli insegnanti di religione, alcuna misura che fissi una durata massima dei contratti o che ne limiti il numero dei possibili rinnovi [ai sensi della clausola 5, par. 1, lett. b) e $c$ )]. Tuttavia, basterebbe accertare l'esistenza delle "ragioni obiettive" di cui alla clausola 5, par. 1, lett. a), per ritenere soddisfatte le indicazioni vincolanti risultanti da questa parte della previsione in esame del diritto dell'Unione.

Cosa sia una "ragione obiettiva", ai sensi della predetta clausola dell'Accordo quadro, non è facile da stabilire.

Si può solo affermare con certezza che non basti una qualificazione meramente formale prevista dalla legge, dovendosi piuttosto avere riguardo alla realtà delle cose, a esigenze concretamente avvertite dal datore di lavoro, che rendano per lui indispensabile non vincolarsi oltre un certo limite con una determinata offerta di lavoro. Si può pensare alle "ragioni di carattere tecnico, produttivo, organizzativo o sostitutivo" che costituivano un tempo la così detta "causalità" giustificativa della stipulazione del contratto a tempo determinato; o alle "esigenze temporanee e oggettive, estranee all'ordinaria attività", ovvero alle "esigenze di sostituzione di altri lavoratori" ovvero, ancora, alle "esigenze connesse a incrementi temporanei, significativi e non programmabili, dell'attività ordinaria", che costituiscono le condizioni di cui parla l'art. 19, primo comma, del decreto legislativo n. 81 del 201567. La Corte di giustizia evoca "circostanze precise e concrete che contraddistinguono una determinata attività" risultanti, ad esempio, dalla "particolare natura delle funzioni", dalle "caratteristiche ad esse inerenti" $\mathrm{o}$, ancora, dal "perseguimento di una legittima finalità di politica sociale di uno Stato

\footnotetext{
${ }^{66}$ Corte di giustizia U.E., 13 gennaio 2022, cit., par. 85.

67 Ricordo che, attualmente, "le causali previste dall'art. 19, comma 1, sono necessarie per qualsiasi rinnovo del CTD o per prorogarlo dopo il $12^{\circ}$ mese come prescrive l'art. 21 , comma 01, d.lgs. n. 81 del 2015, ma anche (sebbene il caso sia stato finora poco praticato) per stipulare un CTD di durata (continuativa) superiore a 12 mesi, ma non eccedente i 24 (art. 19, co. 1)": A. MARESCA, Il contratto a termine?, cit.
} 
membro"68. Ma, più probabilmente, il significato del riferimento alle "ragioni obiettive" non va molto oltre il semplice richiamo a un uso particolarmente accorto del canone della ragionevolezza.

La verifica da compiere con riguardo alla categoria degli insegnanti di religione va condotta con riferimento a due diversi profili della disciplina concernente la loro condizione giuridica.

In primo luogo, va fatta sotto il profilo della necessità del possesso dell'idoneità rilasciata dall'Ordinario diocesano. In altri termini, bisogna accertare se il possesso di quella idoneità costituisca una ragione obiettiva tale da giustificare una disciplina interna che consenta l'assunzione nella scuola pubblica di insegnanti di religione anche attraverso una successione praticamente illimitata di contratti a tempo determinato.

Che l'idoneità in questione sia pienamente coerente con la logica e i contenuti di un insegnamento di carattere confessionale, quale quello disciplinato dalle norme bilaterali tra Stato e Chiesa attualmente in vigore, è fuori discussione; il punto, però, è un altro, e cioè se per rispettare l'impegno assunto dalla Repubblica con la confessione religiosa di assicurare un insegnamento conforme alla dottrina cattolica sia, non solo, necessario (com'è ovvio) prevedere il rilascio dell'attestazione, quale presupposto per la nomina dell'insegnante, e l'eventuale revoca qualora venga meno il rapporto di fiducia implicato dal particolare impegno professionale richiesto, ma anche consentire che la valutazione dell'idoneità sia fatta di anno in anno preliminarmente alla nomina dell'insegnante ${ }^{69}$. Se così fosse, si comprenderebbe pienamente l'esigenza "obiettiva" di una marcata flessibilità di carattere organizzativo nella gestione dell'insegnamento della religione.

A smentire la validità di tale argomentazione, si potrebbe, tuttavia, considerare, come precisato dalla Corte, che l'attestazione dell'idoneità è requisito previsto anche per gli insegnanti di religione assunti a tempo indeterminato ${ }^{70}$. La stessa revoca dell'idoneità è prevista come causa di risoluzione del rapporto di lavoro sia esso a tempo determinato o a tempo

68 Corte di giustizia U.E., 13 gennaio 2022, cit., par. 93.

69 Ricordo che ai sensi del punto 2.7 dell'Intesa del 28 giugno 2012 tra l'Autorità Scolastica e la Conferenza Episcopale Italiana, recepita nell'ordinamento italiano con D.P.R. 20 agosto 2012, n. 175, “[i]l riconoscimento di idoneità all'insegnamento della religione cattolica ha effetto permanente salvo revoca da parte dell'ordinario diocesano". La novità era stata introdotta dall'intesa firmata il 13 giugno 1990 di modifica della prima intesa del 14 dicembre 1985.

${ }^{70}$ Corte di giustizia U.E., 13 gennaio 2022, cit., par. 100. 
indeterminato ${ }^{71}$.

In sostanza e in linea di principio, non si può negare che il requisito del possesso dell'idoneità, sempre suscettibile di essere revocato per ragioni sopravvenute, potrebbe costituire uno di quei peculiari profili della condizione giuridica dell'insegnante di religione meglio "gestibile", nei grandi numeri, applicandolo a contratti aventi durata limitata, anziché a quelli a tempo indeterminato. Basti considerare il diverso "impatto" sull'opinione pubblica che può avere un provvedimento di revoca dell'idoneità e (in presenza dei medesimi presupposti) una mancata conferma di un incarico da rinnovare di anno in anno ${ }^{72}$ : in entrambi i casi l'insegnante non continuerà a svolgere attività didattica; ma la mancata conferma è provvedimento decisamente meno traumatico del primo.

È vero, tuttavia, che la legge di riforma autorizza ormai l'autorità ecclesiastica a continuare a compiere questo tipo di apprezzamenti solo per una quota minoritaria (30\%) della dotazione organica di personale da impegnare nell'insegnamento della religione, a riprova del fatto che non è l'idoneità e la sua possibile revoca a esigere una marcata flessibilità nell'organizzazione e gestione del personale chiamato a insegnare religione.

In secondo luogo, la verifica circa la ricorrenza delle "ragioni obiettive" va condotta con riguardo al carattere facoltativo della materia dell'insegnamento della religione cattolica, che può richiedere, a differenza delle altre materie, o più che in altre materie, un costante adeguamento tra offerta di posti disponibili (dipendente dalle esigenze effettive di utilizzo degli insegnanti) e utenti del servizio pubblico offerto (dipendente dalle scelte fatte dagli studenti o dai loro genitori) e, quindi, una maggiore flessibilità di carattere organizzativo ${ }^{73}$.

${ }^{71}$ Corte di giustizia U.E., 13 gennaio 2022, cit., par. 113.

72 Cfr. P. CAVANA, La riforma dello stato giuridico, cit., p. 1339: prima della legge il venir meno dell'idoneità "poteva tradursi nella mancata conferma dell'incarico annuale alla ripresa dell'anno scolastico, senza bisogno di ricorrere ogni volta ad un atto formale di revoca dell'idoneità con interruzione del rapporto e la pubblicità conseguente". L'A. sottolinea in nota che "[i]n tal modo l'autorità ecclesiastica poteva evitare spiacevoli controversie, limitando l'esercizio della potestà di revoca alle situazioni più gravi di pubblico scandalo, nelle quali risultasse palese la contrarietà del comportamento del docente ai requisiti soggettivi previsti dalla normativa canonica".

73 Ricordo che, ai sensi del punto 2.1 lett. b) dell'Intesa del 28 giugno 2012 cit., "la scelta operata su richiesta dell'autorità scolastica all'atto dell'iscrizione ha effetto per l'intero anno scolastico cui si riferisce e per i successivi anni di corso nei casi in cui è prevista l'iscrizione d'ufficio, fermo restando, anche nelle modalità di applicazione, il diritto di scegliere ogni anno se avvalersi o non avvalersi dell'insegnamento della 
Come si è più sopra precisato, la semplice variazione del numero degli studenti avvalentisi o non avvalentisi non è detto che si ripercuota immediatamente in una fluttuazione dei posti di insegnamento da ricoprire, ma senza dubbio rappresenta un elemento del tutto peculiare di tale insegnamento che può giustificare margini di flessibilità maggiori nella copertura dei posti a tempo indeterminato rispetto alle altre materie. Non dispongo di dati per valutare se la quota del 30 per cento, fissata dalla legge, sia a tale fine congrua, ma si può ragionevolmente affermare che essa non appare affatto sproporzionata o eccessiva.

Bene ha fatto, dunque, la Corte a ritenere sufficientemente dimostrata la ricorrenza delle "ragioni obiettive" di cui alla clausola 5 dell'Accordo quadro ${ }^{74}$, sebbene venga al contempo ribadita nella pronunzia in esame la necessità di una verifica volta ad accertare che l'applicazione concreta della normativa nazionale, pur astrattamente in linea con l'Accordo quadro, non si traduca di fatto in un ricorso abusivo a una successione di contratti non corrispondenti a una reale esigenza di impiego temporaneo del lavoratore ${ }^{75}$.

La Corte conferma così il proprio consolidato orientamento interpretativo incline a pretendere dagli Stati membri " "l'effettiva prevenzione dell'utilizzo abusivo" del termine», senza che possa essere considerato "sufficiente il formale recepimento delle misure indicate dalla direttiva se poi le stesse risultano prive di adeguata effettività"76.

religione cattolica".

L'argomento di cui al testo era stato fatto valere davanti alla Corte di giustizia dal Governo, precisando che «la facoltatività dell'insegnamento della religione cattolica [...] si ripercuoterebbe necessariamente sulla disciplina applicabile al rapporto di lavoro degli insegnanti di religione cattolica. La "domanda" di tale insegnamento sarebbe, in particolare, imprevedibile ed estremamente mutevole nel tempo, anche a breve termine, poiché dipenderebbe in modo integrale dalla scelta degli alunni e/o dei loro genitori di avvalersi o no di detto insegnamento. Il governo italiano ne deduce che il rapporto di lavoro degli insegnanti di religione cattolica deve essere improntato a speciale flessibilità, con la conseguente necessità che circa il 30\% degli insegnanti di religione cattolica stipulino un contratto a tempo determinato» (Corte di giustizia U.E., 13 gennaio 2022, cit., par. 44). "Tale approccio, che consentirebbe quindi di rispondere in modo adeguato alla contrazione della domanda di insegnamento della religione cattolica dovuta a detta facoltatività, sarebbe approvato dalla Corte costituzionale e costituirebbe, inoltre, un'espressione della salvaguardia degli interessi finanziari e organizzativi dello Stato" (ivi, par. 99).

${ }^{74}$ Corte di giustizia U.E., 13 gennaio 2022, cit., par. 104.

${ }^{75}$ Corte di giustizia U.E., 13 gennaio 2022, cit., par. 109.

${ }^{76}$ G. LUDOVICO, Contratto a tempo determinato, cit., p. 84. Ricorda come il principio di effettività funga "da strumento che contribuisce a coordinare la delicata interazione tra 
Finiscono così nel mirino dei giudici, quali indici sintomatici di un possibile abuso, il numero di contratti successivi stipulati con la stessa persona o lo svolgimento di mansioni simili, se non identiche, per svariati anni, da parte degli insegnanti, fattori che non sembrano rispondere, secondo la Corte, a mere esigenze provvisorie del servizio scolastico, ma sembrano piuttosto rientrare nelle necessità della gestione ordinaria del medesimo, con conseguente censura della normativa nazionale nel settore dell'insegnamento pubblico della religione cattolica, in quanto non idonea "a prevenire o a sanzionare gli abusi derivanti dall'utilizzo di una successione di contratti o rapporti di lavoro a tempo determinato"77.

Spetta, tuttavia, al giudice del rinvio accertare la ricorrenza di una situazione del genere, senza che egli possa procedere alla disapplicazione della norma interna contrastante con la clausola $n$. 5 (dato che essa è priva di effetto diretto verticale, a causa della sua non sufficiente precisione e del suo contenuto non incondizionato), ma semmai, come suggerisce la Corte, tentando la via dell'interpretazione conforme del diritto interno al diritto dell'Unione, che però io non vedo come il giudice del rinvio possa concretamente percorrere se, com'è ovvio e come viene correttamente ribadito dai giudici di Lussemburgo, quello strumento "non può servire da fondamento a un'interpretazione contra legem del diritto nazionale"78.

\section{9 - Conclusioni}

$\mathrm{Ci}$ sono delle specificità ineliminabili nella posizione rivestita dall'insegnante di religione rispetto al resto del corpo docente della scuola. La legge n. 186 del 2003 ha fatto quello che ha potuto in fase di assimilazione delle rispettive figure professionali, caratterizzandosi anche per qualche scelta alquanto bizzarra, come quella della previsione (art. 3, quinto comma) del concorso pubblico quale condizione di accesso al ruolo, dal quale resta però escluso l'espletamento di qualsiasi prova

livelli ordinamentali diversi, sovranazionale e nazionale, mediandone gli inevitabili conflitti al fine di salvaguardare l'uniforme applicazione del diritto dell'Unione negli ordinamenti interni", M. AIMO, Il lavoro a termine, cit., p. 13, precisando altresì che quel principio, nell'ambito della disciplina del lavoro a tempo determinato, è il criterio che deve guidare "gli ordinamenti interni nella scelta delle misure che sono obbligatoriamente chiamati a prevedere per recepire, appunto in modo effettivo, le norme di origine europea, anche sotto il profilo sanzionatorio" (ivi, p. 15).

77 Corte di giustizia U.E., 13 gennaio 2022, cit., par. 116.

${ }^{78}$ Corte di giustizia U.E., 13 gennaio 2022, cit., par. 123. 
finalizzata ad accertare le abilità, degli aspiranti a ricoprire i posti, nello svolgere i compiti per i quali il concorso è bandito ${ }^{79}$. Una scelta non obbligata, a differenza di quanto si crede solitamente ${ }^{80}$, potendo, un adeguamento della composizione della commissione giudicatrice ${ }^{81}$, verso il quale, del resto, sembrano orientarsi i più recenti interventi normativi in materia, per di più di origine bilaterale ${ }^{82}$, consentire di superare i problemi di competenza legati alla valutazione dei contenuti di un insegnamento confessionale.

Qualche Autore, all'indomani dell'approvazione della legge n. 186 del 2003, pur prendendo atto dell'impegno dello Stato a garantire l'insegnamento facoltativo della religione cattolica, si è chiesto perché lo stesso Stato "debba spingersi sino ad immetterne nei propri ruoli, come dipendenti con contratto di lavoro a tempo indeterminato, gli insegnanti" 83 . Se non si vuole in questo modo contestare in radice la scelta della Repubblica di farsi carico dell'onere economico di un insegnamento confessionale - e al netto delle palesi forzature o incoerenze presenti nella legge succitata - è facile replicare che, di fronte a un dipendente pubblico, data la preferenza espressa dall'ordinamento per l'assunzione a tempo indeterminato, rafforzata dai vincoli su questo campo derivanti dal diritto dell'Unione europea, non si vede perché debbano legalizzarsi sacche ingiustificate di precariato tra lavoratori impegnati con pari dignità e pari dispendio di energie nel soddisfacimento di quelle che (in modo condivisibile o no), allo stato attuale della legislazione, restano esigenze di specifica rilevanza pubblicistica.

È passando dal quadro dei principi e delle regole alla "concreta

79 Non muta la sostanza del quadro ora descritto l'art. 7 dell'Intesa del 14 dicembre 2020 tra il Ministro dell'istruzione e il Presidente della Conferenza episcopale italiana in tema di "Procedura concorsuale per la copertura dei posti di insegnamento della religione cattolica ai sensi dell'art.1-bis decreto-legge 29 ottobre 2019, n.126, convertito con modificazioni dalla legge 20 dicembre 2019, n. 159", dove si è stabilito che "[n]el rispetto di quanto previsto dall'articolo 3, comma 5, della legge n. 186 del 2003, la preparazione dei candidati è valutata con riferimento ad un programma d'esame comprendente, oltre a quanto previsto nel citato comma 5, anche la conoscenza delle Indicazioni didattiche per l'insegnamento della religione cattolica". Sul punto, cfr. P. NASCENTI, Un'intesa particolare: elementi procedimentali non concordatari in vista del concorso per insegnanti di religione, in Stato, Chiese e pluralismo confessionale, cit., n. 22/2021, p. 68 ss.

80 Ad esempio, S.E. PIZZORNO, Il nuovo stato giuridico, cit., p. 199.

81 Cfr. P. CAVANA, La riforma dello stato giuridico, cit., p. 1333.

${ }^{82}$ Cfr. P. NASCENTI, Un'intesa particolare, cit., p. $70 \mathrm{~s}$.

83 S.E. PIZZORNO, Il nuovo stato giuridico, cit., p. 199. 
applicazione della normativa nazionale", come invita a fare la Corte di giustizia, che cominciano a farsi sentire le dolenti note.

La legge n. 186 del 2003 aveva previsto che i concorsi fossero indetti su base regionale con cadenza triennale (art. 3, secondo comma), ma "[1]a frequenza regolare di un concorso per l'immissione in ruolo degli insegnanti di religione è stata completamente disattesa negli ultimi anni" con "conseguente ingigantimento del precariato" 84 .

Chiedersi, quindi, se la quota del 30\% di insegnanti da assumere con contratto a tempo determinato sia necessaria per garantire la flessibilità di organizzazione di un insegnamento facoltativo significa porsi una domanda che solo in parte va al cuore del problema, prodotto da una non corretta e adeguata applicazione della normativa, più che da una riserva di posti a tempo determinato necessariamente da mantenere, anche per prevenire il rischio che una contrazione del numero dei posti determini l'avvio di procedure di mobilità non pienamente rispettose, secondo l'opinione di molti, delle aspettative legittimamente maturate dagli altri lavoratori della scuola.

In definitiva, la censura proveniente dalla Corte di giustizia sul nostro attuale sistema di reclutamento degli insegnanti di religione, che in qualche modo ne ha "sancito l'incompatibilità "di fatto" [...] rispetto al diritto dell'Unione» 85 , finirà probabilmente con l'incentivare le domande di risarcimento del danno presentate nei casi di più evidente situazione di abuso nella successione di contratti a termine, legittimando indirettamente quell'orientamento giurisprudenziale incline a riconoscere il diritto dell'insegnante a un qualche ristoro, pur in presenza di una norma che, come si è visto, nel caso delle supplenze del personale insegnante, lo esclude espressamente ${ }^{86}$.

${ }^{84}$ P. NASCENTI, Un'intesa particolare, cit., p. 59. Dall'entrata in vigore della legge, si è celebrata un'unica tornata concorsuale: Ministero dell'Istruzione, dell'Università e della Ricerca - Decreto direttoriale del 2 febbraio 2004 di cui all'avviso pubblicato in Gazz. Uff. $4^{a}$ serie spec., 6 febbraio 2004, n. 10, p. 31. Con D.P.C.M. 20 luglio 2021 (in S. CICATELLI, Prontuario giuridico IRC, 10a ed., Queriniana, Brescia, 2020, p. 101 ss. dell'espansione on line), il Ministero dell'istruzione è stato autorizzato ad avviare due procedure concorsuali, di cui una per la scuola primaria e la scuola dell'infanzia, l'altra per la scuola secondaria di primo e secondo grado, per esami e titoli per il reclutamento, nei limiti delle risorse finanziarie disponibili, per gli anni scolastici 2021/2022, 2022/2023 e 2023/2024, di n. 5.116 posti di personale insegnante di religione cattolica.

85 Così (relativamente alla pronunzia Mascolo), M. AIMO, Il lavoro a termine, cit., p. 166.

86 Cfr. Trib. Milano, 10 febbraio 2012, che, pur negando la conversione del contratto, ha però riconosciuto la ricorrenza dei presupposti per un danno risarcibile quantificato in sei mensilità di stipendio: cfr. O. RUSCICA, Sentenza sul ricorso dei docenti di religione 


\section{Corte di Giustizia dell’Unione Europea, sentenza 13 gennaio 2022}

«Rinvio pregiudiziale - Politica sociale - Direttiva 1999/70/CE - Accordo quadro CES, UNICE e CEEP sul lavoro a tempo determinato - Clausole 4 e 5 - Contratti di lavoro a tempo determinato nel settore pubblico - Insegnanti di religione cattolica - Nozione di "ragioni obiettive" per la giustificazione del rinnovo di simili contratti - Fabbisogno permanente di personale supplente»

Nella causa C-282/19,

avente ad oggetto la domanda di pronuncia pregiudiziale proposta alla Corte, ai sensi dell'articolo 267 TFUE, dal Tribunale di Napoli (Italia), con ordinanza del 13 febbraio 2019, pervenuta in cancelleria il 3 aprile 2019, nel procedimento

YT,

ZU,

AW,

BY,

CX,

DZ,

EA,

FB,

GC,

IE,

JF,

KG,

LH,

MI,

NY,

PL,

HD,

OK

contro

Ministero dell'Istruzione, dell'Università e della Ricerca - MIUR,

Ufficio Scolastico Regionale per la Campania,

con l'intervento di:

Federazione GILDA-UNAMS,

LA CORTE (Seconda Sezione),

incaricati annuali: il Tribunale di Milano stabilisce che la condizione di precarietà va risarcita, sul sito www.dirittoscolastico.it (27 febbraio 2012). 
composta da A. Arabadjiev, presidente della Prima Sezione, facente funzione di presidente della Seconda Sezione, I. Ziemele, T. von Danwitz, P.G. Xuereb e A. Kumin (relatore), giudici,

avvocato generale: E. Tanchev

cancelliere: A. Calot Escobar

vista la fase scritta del procedimento,

considerate le osservazioni presentate:

- per YT, ZU, AW, BY, CX, DZ, EA, FB, GC, IE, JF, KG, LH, MI, NY e PL, da S. Tramontano, avvocato;

- per HD, da F. Sorrentino, avvocata;

- per OK, da V. De Michele, avvocato;

- per la Federazione GILDA-UNAMS, da T. de Grandis, avvocato;

- per il governo italiano, da G. Palmieri, in qualità di agente, assistita da L. Fiandaca e P. Gentili, avvocati dello Stato;

- per la Commissione europea, da G. Gattinara, M. van Beek e C. Valero, in qualità di agenti,

sentite le conclusioni dell'avvocato generale, presentate all'udienza del 18 marzo 2021,

ha pronunciato la seguente

\section{Sentenza}

1 La domanda di pronuncia pregiudiziale verte sull'interpretazione delle clausole 4 e 5 dell'accordo quadro sul lavoro a tempo determinato, concluso il 18 marzo 1999 (in prosieguo: $1^{\prime}$ «accordo quadro»), che figura in allegato alla direttiva 1999/70/CE del Consiglio, del 28 giugno 1999, relativa all'accordo quadro CES, UNICE e CEEP sul lavoro a tempo determinato (GU 1999, L 175, pag. 43), dell'articolo 1 e dell'articolo 2, paragrafo 2, lettera a), della direttiva 2000/78/CE del Consiglio, del 27 novembre 2000, che stabilisce un quadro generale per la parità di trattamento in materia di occupazione e di condizioni di lavoro (GU 2000, L 303, pag. 16), e dell'articolo 21 della Carta dei diritti fondamentali dell'Unione europea (in prosieguo: la «Carta»).

2 Tale domanda è stata presentata nell'ambito di una controversia tra, da un lato, YT, ZU, AW, BY, CX, DZ, EA, FB, GC, IE, JF, KG, LH, MI, NY, PL, HD e OK (in prosieguo: $\mathrm{i}$ «ricorrenti di cui al procedimento principale»), insegnanti di religione cattolica presso istituti di istruzione pubblica, e, dall'altro, il 
Ministero dell'Istruzione, dell'Università e della Ricerca - MIUR (Italia) e l'Ufficio Scolastico Regionale per la Campania (Italia), in merito alla loro domanda di conversione del loro contratto di lavoro a tempo determinato in un contratto di lavoro a tempo indeterminato.

\section{Contesto normativo}

\section{Diritto dell'Unione}

\section{Direttiva 1999/70}

3 Ai sensi del considerando 14 della direttiva 1999/70:

«[L]e parti contraenti hanno voluto concludere un accordo quadro sul lavoro a tempo determinato che stabilisce i principi generali e i requisiti minimi per i contratti e i rapporti di lavoro a tempo determinato; hanno espresso l'intenzione di migliorare la qualità del lavoro a tempo determinato garantendo l'applicazione del principio di non discriminazione, nonché di creare un quadro per la prevenzione degli abusi derivanti dall'utilizzo di una successione di contratti o di rapporti di lavoro a tempo determinato».

Accordo quadro

4 Il secondo comma del preambolo dell'accordo quadro stabilisce che le parti firmatarie di quest'ultimo «riconoscono che i contratti a tempo indeterminato sono e continueranno ad essere la forma comune dei rapporti di lavoro fra $i$ datori di lavoro e i lavoratori [e] che i contratti a tempo determinato rispondono, in alcune circostanze, sia alle esigenze dei datori di lavoro sia a quelle dei lavoratori».

5 I punti da 6 a 8 e 10 delle considerazioni generali dell'accordo quadro così recitano:

«6. considerando che i contratti di lavoro a tempo indeterminato rappresentano la forma comune dei rapporti di lavoro e contribuiscono alla qualità della vita dei lavoratori interessati e a migliorare il rendimento;

7. considerando che l'utilizzazione di contratti di lavoro a tempo determinato basata su ragioni oggettive è un modo di prevenire gli abusi;

8. considerando che i contratti di lavoro a tempo determinato rappresentano una caratteristica dell'impiego in alcuni settori, occupazioni e attività atta a soddisfare sia i datori di lavoro sia i lavoratori; 


\section{$(\ldots)$}

10. considerando che il presente accordo demanda agli Stati membri e alle parti sociali la formulazione di disposizioni volte all'applicazione dei principi generali, dei requisiti minimi e delle norme in esso stesso contenuti, al fine di tener conto della situazione di ciascuno Stato membro e delle circostanze relative a particolari settori e occupazioni, comprese le attività di tipo stagionale».

6 Ai sensi della clausola 1 dell'accordo quadro:

«L'obiettivo del presente accordo quadro è:

a) migliorare la qualità del lavoro a tempo determinato garantendo il rispetto del principio di non discriminazione;

b) creare un quadro normativo per la prevenzione degli abusi derivanti dall'utilizzo di una successione di contratti o rapporti di lavoro a tempo determinato».

7 La clausola 2 dell'accordo quadro, intitolata «Campo d'applicazione», al punto 1 prevede quanto segue:

«Il presente accordo si applica ai lavoratori a tempo determinato con un contratto di assunzione o un rapporto di lavoro disciplinato dalla legge, dai contratti collettivi o dalla prassi in vigore di ciascuno Stato membro».

8 La clausola 3 dell'accordo quadro, intitolata «Definizioni», così dispone:

«1. Ai fini del presente accordo, il termine "lavoratore a tempo determinato" indica una persona con un contratto o un rapporto di lavoro definiti direttamente fra il datore di lavoro e il lavoratore e il cui termine è determinato da condizioni oggettive, quali il raggiungimento di una certa data, il completamento di un compito specifico o il verificarsi di un evento specifico.

$(\ldots) \gg$.

9 La clausola 4 dell'accordo quadro, intitolata «Principio di non discriminazione», al punto 1 prevede quanto segue:

«Per quanto riguarda le condizioni di impiego, i lavoratori a tempo determinato non possono essere trattati in modo meno favorevole dei lavoratori a tempo indeterminato comparabili per il solo fatto di avere un 
contratto o rapporto di lavoro a tempo determinato, a meno che non sussistano ragioni oggettive».

10 La clausola 5 dell'accordo quadro, intitolata «Misure di prevenzione degli abusi», così recita:

«1. Per prevenire gli abusi derivanti dall'utilizzo di una successione di contratti o rapporti di lavoro a tempo determinato, gli Stati membri, previa consultazione delle parti sociali a norma delle leggi, dei contratti collettivi e della prassi nazionali, e/o le parti sociali stesse, dovranno introdurre, in assenza di norme equivalenti per la prevenzione degli abusi e in un modo che tenga conto delle esigenze di settori e/o categorie specifici di lavoratori, una o più misure relative $\mathrm{a}$ :

a) ragioni obiettive per la giustificazione del rinnovo dei suddetti contratti o rapporti;

b) la durata massima totale dei contratti o rapporti di lavoro a tempo determinato successivi;

c) il numero dei rinnovi dei suddetti contratti o rapporti.

2. Gli Stati membri, previa consultazione delle parti sociali, e/o le parti sociali stesse dovranno, se del caso, stabilire a quali condizioni i contratti e i rapporti di lavoro a tempo determinato:

a) devono essere considerati "successivi";

b) devono essere ritenuti contratti o rapporti a tempo indeterminato».

11 La clausola 8 dell'accordo quadro, intitolata «Disposizioni di attuazione», è del seguente tenore:

«1. Gli Stati membri e/o le parti sociali possono mantenere o introdurre disposizioni più favorevoli per i lavoratori di quelle stabilite nel presente [accordo quadro].

$(\ldots) »$.

Direttiva 2000/78

12 Il considerando 24 della direttiva 2000/78 così recita: 
«L'Unione europea, nella dichiarazione n. 11 sullo status delle chiese e delle organizzazioni non confessionali allegata all'atto finale del trattato di Amsterdam, ha riconosciuto espressamente che rispetta e non pregiudica lo status previsto nelle legislazioni nazionali per le chiese e le associazioni o comunità religiose degli Stati membri e inoltre che rispetta lo status delle organizzazioni filosofiche e non confessionali. In tale prospettiva, gli Stati membri possono mantenere o prevedere disposizioni specifiche sui requisiti professionali essenziali, legittimi e giustificati che possono essere imposti per svolgervi un'attività lavorativa».

13 L'articolo 1 di tale direttiva dispone che essa mira a stabilire un quadro generale per la lotta alle discriminazioni fondate, in particolare, sulla religione o le convinzioni personali, per quanto concerne l'occupazione e le condizioni di lavoro, al fine di rendere effettivo negli Stati membri il principio della parità di trattamento.

14 L'articolo 2, paragrafi 1 e 2, della direttiva succitata prevede quanto segue:

«1. Ai fini della presente direttiva, per "principio della parità di trattamento" si intende l'assenza di qualsiasi discriminazione diretta o indiretta basata su uno dei motivi di cui all'articolo 1.

2. Ai fini del paragrafo 1:

a) sussiste discriminazione diretta quando, sulla base di uno qualsiasi dei motivi di cui all'articolo 1, una persona è trattata meno favorevolmente di quanto sia, sia stata o sarebbe trattata un'altra in una situazione analoga;

b) sussiste discriminazione indiretta quando una disposizione, un criterio o una prassi apparentemente neutri possono mettere in una posizione di particolare svantaggio le persone che professano una determinata religione o ideologia di altra natura, le persone portatrici di un particolare handicap, le persone di una particolare età o di una particolare tendenza sessuale, rispetto ad altre persone, a meno che:

i) tale disposizione, tale criterio o tale prassi siano oggettivamente giustificati da una finalità legittima e i mezzi impiegati per il suo conseguimento siano appropriati e necessari; (...)

$(\ldots) »$.

\section{Diritto italiano}


15 L'articolo 3, commi 4, 7, 8 e 9, della legge del 18 luglio 2003, n. 186 - Norme sullo stato giuridico degli insegnanti di religione cattolica degli istituti e delle scuole di ogni ordine e grado (GURI n. 170, del 24 luglio 2003), così dispone:

«4. Ciascun candidato [a un concorso] deve (...) essere in possesso del riconoscimento di idoneità (...) rilasciato dall'ordinario diocesano competente per territorio e può concorrere soltanto per i posti disponibili nel territorio di pertinenza della diocesi.

7. Le commissioni compilano l'elenco di coloro che hanno superato il concorso, valutando, oltre al risultato delle prove, esclusivamente i titoli (...). Il dirigente regionale approva l'elenco ed invia all'ordinario diocesano competente per territorio i nominativi di coloro che si trovano in posizione utile per occupare i posti delle dotazioni organiche (...). Dall'elenco dei docenti che hanno superato il concorso il dirigente regionale attinge per segnalare all'ordinario diocesano i nominativi necessari per coprire i posti che si rendano eventualmente vacanti nelle dotazioni organiche durante il periodo di validità del concorso.

8. L'assunzione con contratto di lavoro a tempo indeterminato è disposta dal dirigente regionale, $d$ 'intesa con l'ordinario diocesano competente per territorio (...).

9. Ai motivi di risoluzione del rapporto di lavoro previsti dalle disposizioni vigenti si aggiunge la revoca dell'idoneità da parte dell'ordinario diocesano competente per territorio divenuta esecutiva a norma dell'ordinamento canonico (...)».

16 L'articolo 36, commi 1, 2 e 5, del decreto legislativo del 30 marzo 2001, n. 165 Norme generali sull'ordinamento del lavoro alle dipendenze delle amministrazioni pubbliche (Supplemento ordinario alla GURI n. 106 del 9 maggio 2001), nella versione applicabile al procedimento principale (in prosieguo: il «decreto legislativo n. 165/2001»), così disponeva:

«1. Per le esigenze connesse con il proprio fabbisogno ordinario le pubbliche amministrazioni assumono esclusivamente con contratti di lavoro subordinato a tempo indeterminato (...).

2. Per rispondere ad esigenze di carattere esclusivamente temporaneo o eccezionale le amministrazioni pubbliche possono avvalersi delle forme contrattuali flessibili di assunzione e di impiego del personale previste dal 
codice civile e dalle leggi sui rapporti di lavoro subordinato nell'impresa, nel rispetto delle procedure di reclutamento vigenti.

\section{$(\ldots)$}

5. In ogni caso, la violazione di disposizioni imperative riguardanti l'assunzione o l'impiego di lavoratori, da parte delle pubbliche amministrazioni, non può comportare la costituzione di rapporti di lavoro a tempo indeterminato con le medesime pubbliche amministrazioni, ferma restando ogni responsabilità e sanzione. Il lavoratore interessato ha diritto al risarcimento del danno derivante dalla prestazione di lavoro in violazione di disposizioni imperative».

17 L'articolo 5, commi 2 e 4-bis, del decreto legislativo del 6 settembre 2001, n. 368 - Attuazione della direttiva 1999/70/CE relativa all'accordo quadro sul lavoro a tempo determinato concluso dall'UNICE, dal CEEP e dal CES (GURI n. 235 del 9 ottobre 2001), nella versione applicabile al procedimento principale (in prosieguo: il «decreto legislativo n. 368/2001», così disponeva:

«2. Se il rapporto di lavoro continua oltre il trentesimo giorno in caso di contratto di durata inferiore a sei mesi nonché decorso il periodo complessivo di cui al comma 4-bis, ovvero oltre il cinquantesimo giorno negli altri casi, il contratto si considera a tempo indeterminato dalla scadenza dei predetti termini.

\section{$(\ldots)$}

4-bis. (...) qualora per effetto di successione di contratti a termine per lo svolgimento di mansioni equivalenti il rapporto di lavoro fra lo stesso datore di lavoro e lo stesso lavoratore abbia complessivamente superato i trentasei mesi comprensivi di proroghe e rinnovi, indipendentemente dai periodi di interruzione che intercorrono tra un contratto e l'altro, il rapporto di lavoro si considera a tempo indeterminato ai sensi del comma $2 ;(.)$.$» .$

18 L'articolo 10, comma 4-bis, del decreto legislativo n. 368/2001 così disponeva:

«(...) sono (...) esclusi dall'applicazione del presente decreto i contratti a tempo determinato stipulati per il conferimento delle supplenze del personale docente [e del personale amministrativo, tecnico e ausiliario; in prosieguo: "ATA"], considerata la necessità di garantire la costante erogazione del servizio scolastico ed educativo anche in caso di assenza temporanea del personale docente ed ATA con rapporto di lavoro a tempo indeterminato ed anche determinato. (...)». 
19 Il decreto legislativo del 15 giugno 2015, n. 81 - Disciplina organica dei contratti di lavoro e revisione della normativa in tema di mansioni, a norma dell'articolo 1, comma 7, della legge 10 dicembre 2014, n. 183 (Supplemento ordinario alla GURI n. 144 del 24 giugno 2015) (in prosieguo: il «decreto legislativo n. 81/2015»), che ha abrogato e sostituito il decreto legislativo n. $368 / 2001$, ha ripreso, in sostanza, all'articolo 19, la stessa disposizione di cui all'articolo 5, comma 4-bis, di quest'ultimo decreto legislativo. Tale articolo 19 era del seguente tenore:

«1. Al contratto di lavoro subordinato può essere apposto un termine di durata non superiore a trentasei mesi.

2 Fatte salve le diverse disposizioni dei contratti collettivi, (...) la durata dei rapporti di lavoro a tempo determinato intercorsi tra lo stesso datore di lavoro e lo stesso lavoratore, per effetto di una successione di contratti, conclusi per lo svolgimento di mansioni di pari livello e categoria legale e indipendentemente dai periodi di interruzione tra un contratto e l'altro, non può superare i trentasei mesi. (...) Qualora il limite dei trentasei mesi sia superato, per effetto di un unico contratto o di una successione di contratti, il contratto si trasforma in contratto a tempo indeterminato dalla data di tale superamento».

20 L'articolo 29, comma 2, lettera c), del decreto legislativo n. 81/2015 riprende, in sostanza, il tenore letterale dell'articolo 10, comma 4-bis, del decreto legislativo n. 368/2001, nella misura in cui dispone che sono altresì esclusi dal campo di applicazione del capo III del decreto legislativo n. 81/2015, relativo al lavoro a tempo determinato, i contratti a tempo determinato stipulati con il personale docente e ATA per il conferimento delle supplenze.

21 L'articolo 309 del decreto legislativo del 16 aprile 1994, n. 297 - Approvazione del testo unico delle disposizioni legislative vigenti in materia di istruzione, relative alle scuole di ogni ordine e grado (Supplemento ordinario alla GURI n. 115 del 19 maggio 1994; in prosieguo: il «decreto legislativo n. 297/1994»), così dispone:

«1. Nelle scuole pubbliche non universitarie di ogni ordine e grado l'insegnamento della religione cattolica è disciplinato dall'accordo tra la Repubblica Italiana e la Santa Sede e relativo protocollo addizionale, (...) e dalle intese previste dal predetto protocollo addizionale, punto 5, lettera b).

2. Per l'insegnamento della religione cattolica il capo di istituto conferisce incarichi annuali d'intesa con l'ordinario diocesano secondo le disposizioni richiamate nel comma 1 ». 
22 L'articolo 399 di tale decreto legislativo dispone che l'accesso ai ruoli del personale docente della scuola materna, elementare e secondaria, ivi compresi i licei artistici e gli istituti d'arte, ha luogo, per la metà dei posti a tal fine annualmente assegnabili, mediante concorsi per titoli ed esami e, per la restante metà, attingendo alle graduatorie permanenti di cui all'articolo 401 . Nel caso in cui la graduatoria di un concorso per titoli ed esami sia esaurita e rimangano posti ad esso assegnati, questi vanno ad aggiungersi a quelli assegnati alla corrispondente graduatoria permanente. Detti posti vanno reintegrati in occasione della procedura concorsuale successiva.

23 L'articolo 1, comma 95, della legge del 13 luglio 2015, n. 107 - Riforma del sistema nazionale di istruzione e formazione e delega per il riordino delle disposizioni legislative vigenti (GURI n. 162 del 15 luglio 2015; in prosieguo: la «legge n. 107/2015»), dispone che, per l'anno scolastico 2015/2016, il MIUR è autorizzato ad attuare un piano straordinario di assunzioni a tempo indeterminato di personale docente per le istituzioni scolastiche statali di ogni ordine e grado, per la copertura di tutti i posti comuni e di sostegno dell'organico «di diritto», rimasti vacanti e disponibili all'esito delle operazioni di immissione in ruolo effettuate per il medesimo anno scolastico ai sensi dell'articolo 399 del decreto legislativo n. 297/1994, al termine delle quali sono soppresse le graduatorie dei concorsi per titoli ed esami banditi anteriormente al 2012.

24 L'articolo 40, commi 1 e 5, del contratto collettivo nazionale di lavoro relativo al personale del comparto scuola, del 29 novembre 2007, integrato dal contratto collettivo nazionale del lavoro del 19 aprile 2018, (Supplemento ordinario alla GURI n. 292 del 17 dicembre 2007; in prosieguo: il «CCNL»), stabilisce quanto segue:

«1. Al personale di cui al presente articolo, si applicano le disposizioni di cui ai commi 2, 3, e 4 dell'art. 25.

5. Gli insegnanti di religione cattolica sono assunti secondo la disciplina di cui all'art. 309 del decreto legislativo [n. 297/1994], mediante contratto di incarico annuale che si intende confermato qualora permangano le condizioni ed i requisiti prescritti dalle vigenti disposizioni di legge».

25 L'articolo 25, comma 3, del CCNL prevede quanto segue:

«I rapporti individuali di lavoro a tempo indeterminato o determinato del personale docente ed educativo degli istituti e scuole statali di ogni ordine e grado, sono costituiti e regolati da contratti individuali, nel rispetto delle 
disposizioni di legge, della normativa comunitaria e del contratto collettivo nazionale vigente».

\section{Procedimento principale e questioni pregiudiziali}

26 I ricorrenti di cui al procedimento principale sono insegnanti di religione cattolica assunti dal MIUR e impiegati presso istituti di istruzione pubblica da svariati anni mediante una successione di contratti a tempo determinato.

27 Ritenendo che tale successione di contratti a tempo determinato sia illegittima e constatando di non aver potuto beneficiare del meccanismo di immissione in ruolo previsto all'articolo 399 del decreto legislativo n. 297/1994, i ricorrenti di cui al procedimento principale sostengono di essere vittime di una discriminazione rispetto ai docenti di altre materie. Essi hanno pertanto proposto ricorso dinanzi al giudice del rinvio al fine di ottenere, in forza dell'articolo 5, commi 2 e 4-bis, del decreto legislativo n. 368/2001, la conversione dei loro attuali contratti in contratti a tempo indeterminato $\mathrm{o}$, in subordine, il risarcimento del danno subìto a causa della stipulazione di una successione di contratti a tempo determinato.

28 La Federazione GILDA-UNAMS, associazione professionale e sindacale di insegnanti, intervenuta nel procedimento principale in qualità di organizzazione sindacale firmataria del CCNL, sostiene, in particolare, che gli insegnanti di religione cattolica sono vittime di discriminazione per via dell'impossibilità di conversione del loro rapporto di lavoro a tempo determinato in rapporto di lavoro a tempo indeterminato, pur essendo essi in possesso della stessa idoneità all'insegnamento degli altri docenti.

29 Il giudice del rinvio ritiene che nessuna delle domande dei ricorrenti di cui al procedimento principale possa essere accolta alla luce del diritto italiano.

30 A tale riguardo, esso precisa anzitutto che, alla data di deposito del ricorso dei ricorrenti di cui al procedimento principale, i loro rispettivi contratti di lavoro avevano tutti una durata complessiva superiore ai 36 mesi. Orbene, benché, in tal caso, in linea di principio, il decreto legislativo n. 368/2001 preveda la conversione dei contratti a tempo determinato successivi in contratto a tempo indeterminato, l'articolo 36, comma 5, del decreto legislativo n. 165/2001 escluderebbe tuttavia espressamente una tale conversione nel settore del pubblico impiego.

31 Esso rileva poi che, sebbene la successione continuativa di contratti di lavoro a tempo determinato oltre i 36 mesi possa inoltre, in forza dell'articolo 36, comma 5, del decreto legislativo n. 165/2001, essere sanzionata mediante il risarcimento del danno subìto dal lavoratore a causa di tale successione, 
l'articolo 10, comma 4-bis, del decreto legislativo n. 368/2001 escluderebbe tuttavia una simile possibilità nel settore dell'insegnamento, come l'articolo 29, comma 2, del decreto legislativo n. 81/2015 avrebbe ulteriormente confermato.

32 Inoltre, il giudice del rinvio sottolinea che i ricorrenti nel procedimento principale non hanno potuto beneficiare dell'immissione in ruolo né in forza dell'articolo 399 del decreto legislativo n. 297/1994 né in forza della legge n. $107 / 2015$, la quale ha consentito una generale regolarizzazione del personale docente precario, autorizzando la conclusione di contratti a tempo indeterminato.

33 Da tali elementi emergerebbe che il diritto italiano non prevede alcuna misura di prevenzione dell'utilizzo abusivo di una successione di contratti di lavoro a tempo determinato, ai sensi della clausola 5 dell'accordo quadro, per gli insegnanti di religione cattolica impiegati presso istituti pubblici. Il giudice del rinvio si chiede, pertanto, se il diritto italiano sia conforme al diritto dell'Unione.

34 A questo proposito, esso riferisce che, secondo la costante giurisprudenza della Corte suprema di cassazione (Italia), l'articolo 10, comma 4-bis, del decreto legislativo n. 368/2001, che è lex specialis, esclude, nel settore dell'insegnamento, la conversione dei contratti a tempo determinato, stipulati per il conferimento delle supplenze, in contratti a tempo indeterminato.

$35 \mathrm{Il}$ giudice del rinvio precisa altresì che, secondo la Corte costituzionale (Italia), che ha eseguito un controllo di legittimità costituzionale dell'articolo 10, comma 4-bis, del decreto legislativo n. 368/2001 e dell'articolo 36, comma 5, del decreto legislativo n. 165/2001, sarebbe impossibile, nel settore del pubblico impiego, convertire un rapporto di lavoro a tempo determinato in un rapporto di lavoro a tempo indeterminato.

36 Secondo il giudice del rinvio, tale giurisprudenza sarebbe contraria a quella derivante dalla sentenza del 25 ottobre 2018, Sciotto (C-331/17, EU:C:2018:859), con la quale la Corte avrebbe concluso che la clausola 5 dell'accordo quadro deve essere interpretata nel senso che essa osta a una normativa nazionale in forza della quale non sono applicabili al settore di attività delle fondazioni lirico-sinfoniche le norme di diritto comune disciplinanti i rapporti di lavoro e intese a sanzionare il ricorso abusivo a una successione di contratti a tempo determinato attraverso la conversione automatica di contratti a tempo determinato in contratti a tempo indeterminato, nel caso in cui il rapporto di lavoro perduri oltre una certa data, qualora non esista nessun'altra misura effettiva nell'ordinamento giuridico interno che sanzioni gli abusi constatati in tale settore. 
37 Infine, il giudice del rinvio ricorda che l'insegnamento della religione cattolica è subordinato al rilascio all'insegnante, da parte dell'ordinario diocesano, di un «riconoscimento di idoneità» (in prosieguo: $1^{\prime}$ «idoneità» o il «titolo di idoneità»), che non sia stato revocato. La revoca dell'idoneità costituirebbe quindi un motivo valido di licenziamento, aspetto che comproverebbe ulteriormente la precarietà del rapporto di lavoro di un insegnante di religione cattolica.

38 Ciò considerato, il Tribunale di Napoli (Italia) ha deciso di sospendere il procedimento e di sottoporre alla Corte le seguenti questioni pregiudiziali:

«1) Se il diverso trattamento riservato ai soli insegnanti di religione cattolica, quali gli istanti [nel procedimento principale], costituisca discriminazione per motivi religiosi, ai sensi dell'articolo 21 della Carta (...) e della direttiva [2000/78] ovvero se la circostanza che [1']idoneità già in possesso del lavoratore possa essere revocata sia ragione giustificatrice idonea perché solo gli insegnanti di religione cattolica, quali gli istanti [nel procedimento principale], siano trattati diversamente dagli altri docenti, non beneficiando di alcuna misura ostativa prevista dalla Clausola 5 dell'accordo quadro (...);

2) n ipotesi di ritenuta sussistenza di discriminazione diretta, ai sensi dell'articolo 2, paragrafo 2, lettera a), della direttiva [2000/78], per motivi religiosi (articolo 1), nonché ai sensi della Carta (...), deve interrogarsi la Corte circa gli strumenti che questo giudice può adoperare per eliminarne le conseguenze, tenuto conto che tutti i docenti diversi dagli insegnanti di religione cattolica sono stati destinatari del piano straordinario di assunzioni di cui alla legge 107/15, ottenendo la immissione in ruolo con conseguente contratto di lavoro a tempo indeterminato, e, dunque, se questo giudice debba costituire un rapporto di lavoro a tempo indeterminato con la Amministrazione convenuta [nel procedimento principale];

3) se la clausola 5 dell'accordo quadro (...) debba essere interpretata nel senso che essa osta ad una normativa nazionale, come quella di cui trattasi, in forza della quale le norme di diritto comune disciplinanti i rapporti di lavoro, intese a sanzionare il ricorso abusivo a una successione di contratti a tempo determinato tramite la conversione automatica del contratto a tempo determinato in un contratto a tempo indeterminato qualora il rapporto di lavoro perduri oltre una data precisa, non sono applicabili al settore scuola, con specifico riferimento ai docenti di religione cattolica, in modo tale da consentire una successione di contratti di lavoro a tempo determinato per un periodo di tempo indefinito; in particolare se possa costituire ragione obiettiva ai sensi della clausola 5, punto 1, lettera a), dell'accordo quadro la necessità d'intesa con l'ordinario diocesano, ovvero, di contro, debba ritenersi una discriminazione vietata ai sensi dell'articolo 21 della [Carta]; 
4) in ipotesi di risposta positiva al quesito sub 3 se l'articolo 21 della [Carta], la clausola 4 dell'accordo quadro (...) e/o l'articolo 1 della direttiva [2000/78] consentano la disapplicazione [delle] norme che impediscono la conversione automatica di un contratto a tempo determinato in un contratto a tempo indeterminato qualora il rapporto di lavoro perduri oltre una data precisa».

\section{Sulla competenza della Corte}

39 Il governo italiano, invocando l'articolo 17, paragrafo 1, TFUE, ritiene che la Corte non sia competente a rispondere alle questioni pregiudiziali sottopostele dal giudice del rinvio, in quanto tali questioni riguardano i rapporti tra l'ordinamento giuridico della Repubblica italiana e un ordinamento giuridico confessionale, nella fattispecie l'ordinamento giuridico della Chiesa cattolica, rapporti che rientrano esclusivamente nell'ambito del diritto interno.

40 L'articolo 17, paragrafo 1, TFUE imporrebbe un obbligo di rispetto dello status di cui godono, in virtù del diritto nazionale, in particolare le chiese, che si tradurrebbe in una non ingerenza nelle questioni strettamente religiose e che sarebbe stato sancito dalla Corte EDU nella sua sentenza del 15 maggio 2012, Fernández Martínez c. Spagna (CE:ECHR:2012:0515JUD005603007).

$41 \mathrm{Nel}$ caso di specie, il rapporto di lavoro tra l'istituto scolastico di cui trattasi e gli insegnanti di religione cattolica sarebbe disciplinato dall'Accordo di revisione del Concordato, stipulato il 18 febbraio 1984 tra la Repubblica italiana e la Santa Sede (in prosieguo: il «Concordato»), e dal suo protocollo addizionale. Ai sensi del punto 5 di quest'ultimo, l'insegnamento della religione cattolica sarebbe impartito da insegnanti che siano riconosciuti idonei dall'autorità ecclesiastica, nominati, d'intesa con essa, dall'autorità scolastica.

42 Secondo il canone 804, § 2, del codice di diritto canonico, l'ordinario del luogo veglierebbe a che coloro i quali sono deputati come insegnanti della religione nelle scuole, anche non cattoliche, siano eccellenti per retta dottrina, per testimonianza di vita cristiana e per abilità pedagogica. Sarebbe quindi pacifico che esiste un nesso tra, da un lato, l'idoneità e, dall'altro, l'assunzione e la permanenza dell'insegnante di religione cattolica nel rapporto di lavoro.

$43 \mathrm{Ne}$ conseguirebbe che la constatazione della sussistenza di una discriminazione, ai sensi della direttiva 2000/78, nei confronti degli insegnanti di religione cattolica degli istituti di istruzione pubblica comporterebbe necessariamente un inadempimento dell'obbligo di non ingerenza che sarebbe espressamente sancito dall'articolo 17 TFUE. 
44 Ciò premesso, il governo italiano sottolinea la facoltatività dell'insegnamento della religione cattolica, come risulta, in particolare, dall'articolo 9, comma 2, del Concordato, confermata altresì dalla Corte costituzionale. Tale facoltatività si ripercuoterebbe necessariamente sulla disciplina applicabile al rapporto di lavoro degli insegnanti di religione cattolica. La «domanda» di tale insegnamento sarebbe, in particolare, imprevedibile ed estremamente mutevole nel tempo, anche a breve termine, poiché dipenderebbe in modo integrale dalla scelta degli alunni e/o dei loro genitori di avvalersi o no di detto insegnamento. Il governo italiano ne deduce che il rapporto di lavoro degli insegnanti di religione cattolica deve essere improntato a speciale flessibilità, con la conseguente necessità che circa il 30\% degli insegnanti di religione cattolica stipulino un contratto a tempo determinato.

45 Inoltre, il governo italiano ricorda che l'articolo 351 TFUE prevede che le disposizioni dei trattati non pregiudicano i diritti e gli obblighi derivanti da convenzioni concluse, anteriormente al $1^{\circ}$ gennaio 1958, tra uno o più Stati membri, da una parte, e uno o più Stati terzi, dall'altra. Orbene, 1'Accordo del 1984 avrebbe modificato il Concordato del 1929, il cui articolo 36 prevedeva già che l'insegnamento della religione cattolica fosse affidato a personale che avesse ottenuto l'approvazione dell'autorità ecclesiastica o, comunque, che fosse munito di un certificato di idoneità rilasciato dall'ordinario diocesano, la cui revoca era sufficiente a privare l'insegnante dell'idoneità a insegnare.

46 A questo proposito, occorre ricordare, in primo luogo, che, a norma dell'articolo 17, paragrafo 1, TFUE, $1^{\prime}$ Unione rispetta e non pregiudica lo status di cui le chiese e le associazioni o comunità religiose godono negli Stati membri in virtù del diritto nazionale.

$47 \mathrm{Da}$ tale disposizione non consegue tuttavia, come ha dichiarato la Corte, che una differenza di trattamento contenuta in una normativa nazionale, che prevede la concessione a taluni lavoratori di un giorno festivo destinato a consentire la celebrazione di una festa religiosa, sia esclusa dall'ambito di applicazione della direttiva 2000/78 e che la conformità di una tale differenza di trattamento a questa direttiva esuli da un sindacato giurisdizionale effettivo (sentenza del 22 gennaio 2019, Cresco Investigation, C-193/17, EU:C:2019:43, punto 31).

48 Allo stesso modo, la suddetta disposizione non può implicare che un'eventuale differenza di trattamento, contenuta nella normativa nazionale che prevede sanzioni in caso di abuso nell'utilizzo di una successione di contratti a tempo determinato negli istituti di istruzione pubblica tra gli insegnanti di religione cattolica di tali istituti e gli altri docenti, sia esclusa dall'ambito di applicazione sia di tale direttiva sia dell'accordo quadro. 
49 Infatti, da un lato, la formulazione dell'articolo 17 TFUE corrisponde, in sostanza, a quella della dichiarazione $\mathrm{n}$. 11 sullo status delle chiese e delle organizzazioni non confessionali, allegata all'atto finale del Trattato di Amsterdam. Orbene, il fatto che quest'ultima sia esplicitamente citata al considerando 24 della direttiva 2000/78 mette in risalto che il legislatore dell'Unione ha necessariamente tenuto conto di detta dichiarazione al momento di adottare la suddetta direttiva (sentenza del 22 gennaio 2019, Cresco Investigation, C-193/17, EU:C:2019:43, punto 32 e giurisprudenza ivi citata).

50 Dall'altro lato, l'articolo 17 TFUE esprime, certo, la neutralità dell'Unione nei confronti dell'organizzazione, da parte degli Stati membri, dei loro rapporti con le chiese e le associazioni o comunità religiose (sentenze del 17 aprile 2018, Egenberger, C-414/16, EU:C:2018:257, punto 58; dell'11 settembre 2018, IR, C-68/17, EU:C:2018:696, punto 48, e del 22 gennaio 2019, Cresco Investigation, C-193/17, EU:C:2019:43, punto 33).

51 Tuttavia, occorre constatare che le disposizioni nazionali di cui al procedimento principale non sono dirette a organizzare i rapporti tra uno Stato membro e le chiese, nella fattispecie la chiesa cattolica, ma riguardano le condizioni di lavoro degli insegnanti di religione cattolica presso gli istituti pubblici (v., per analogia, sentenza del 22 gennaio 2019, Cresco Investigation, C-193/17, EU:C:2019:43, punto 33).

52 Esiste senz'altro, come sostiene la Repubblica italiana, un nesso tra, da un lato, l'idoneità rilasciata agli insegnanti di religione cattolica e, dall'altro, l'assunzione e la permanenza di tali insegnanti nel rapporto di lavoro. Tuttavia, non soltanto il rilascio e la revoca di tale idoneità, nonché le conseguenze che possono derivarne, presentano un nesso con l'assunzione e la permanenza di detti insegnanti nel rapporto di lavoro, ma inoltre la competenza dell'ordinario diocesano non è messa in discussione dalle disposizioni menzionate nelle questioni pregiudiziali e permarrà, a prescindere dal fatto che i ricorrenti nel procedimento principale riescano o no a ottenere la conversione del loro contratto a tempo determinato in contratto a tempo indeterminato. Inoltre, l'applicazione dell'accordo quadro ai fatti di cui al procedimento principale non richiede una pronuncia sulla facoltatività dell'insegnamento della religione cattolica.

53 Ne consegue che nel procedimento principale non è in discussione lo «status» di cui godono, in virtù del diritto italiano, le chiese menzionate all'articolo 17, paragrafo 1, TFUE, quale, nel caso di specie, la Chiesa cattolica.

54 La competenza della Corte nella presente causa non può essere rimessa in discussione neppure dall'articolo 351, paragrafo 1, TFUE, ai sensi del quale 
«[l]e disposizioni dei trattati non pregiudicano i diritti e gli obblighi derivanti da convenzioni concluse, anteriormente al $1^{\circ}$ gennaio 1958 o, per gli Stati aderenti, anteriormente alla data della loro adesione, tra uno o più Stati membri da una parte e uno o più Stati terzi dall'altra».

55 Occorre ricordare, a tale riguardo, che tale disposizione mira a consentire agli Stati membri di rispettare i diritti che, in conformità del diritto internazionale, gli Stati terzi vantano sulla base delle suddette convenzioni precedenti [parere 2/15 (Accordo di libero scambio con Singapore), del 16 maggio 2017, EU:C:2017:376, punto 254 e giurisprudenza ivi citata].

56 Orbene, come rilevato dall'avvocato generale al paragrafo 43 delle conclusioni, detta disposizione non è pertinente ai fini del procedimento principale, in quanto gli accordi conclusi con la Santa Sede o ad essa connessi riguardano la competenza degli ordinari diocesani a emettere e revocare l'idoneità all'insegnamento della religione cattolica, competenza che non è messa in discussione, come risulta dal punto 52 della presente sentenza, dalle disposizioni menzionate nelle questioni pregiudiziali, in particolare dalla clausola 5 dell'accordo quadro.

57 Ciò posto, si deve ritenere che la Corte sia competente a statuire sulla domanda di pronuncia pregiudiziale.

\section{Sulle questioni pregiudiziali}

58 Con le questioni pregiudiziali poste, che è opportuno esaminare congiuntamente, il giudice del rinvio chiede, in sostanza, da un lato, se il divieto di discriminazione fondata sulla religione, ai sensi della direttiva 2000/78 e dell'articolo 21 della Carta, nonché la clausola 5 dell'accordo quadro debbano essere interpretati nel senso che essi ostano a una normativa nazionale che esclude gli insegnanti di religione cattolica degli istituti di istruzione pubblica dall'applicazione delle norme dirette a sanzionare il ricorso abusivo a una successione di contratti a tempo determinato, e, dall'altro, se tale clausola debba essere interpretata nel senso che la necessità di un'idoneità rilasciata da un'autorità ecclesiastica al fine di consentire a tali insegnanti di impartire l'insegnamento della religione cattolica costituisca una «ragione obiettiva» ai sensi del punto 1, lettera a), della medesima clausola.

59 Occorre ricordare anzitutto che, conformemente all'articolo 1 della direttiva $2000 / 78$, e come risulta sia dal titolo e dal preambolo sia dal contenuto e dalla finalità della stessa, tale direttiva mira a stabilire un quadro generale per la lotta alle discriminazioni fondate, segnatamente, sulla religione per quanto concerne l'occupazione e le condizioni di lavoro, al fine di rendere effettivo negli Stati membri il principio della parità di trattamento, offrendo ad ogni persona una 
tutela efficace contro le discriminazioni fondate, in particolare, su tale motivo di discriminazione (v., in tal senso, sentenza del 26 gennaio 2021, Szpital Kliniczny im. dra J. Babińskiego Samodzielny Publiczny Zakład Opieki Zdrowotnej w Krakowie, C-16/19, EU:C:2021:64, punto 32).

60 Tale direttiva concretizza dunque, nel settore da essa disciplinato, il principio generale di non discriminazione ora sancito dall'articolo 21 della Carta (sentenza del 26 gennaio 2021, Szpital Kliniczny im. dra J. Babińskiego Samodzielny Publiczny Zakład Opieki Zdrowotnej w Krakowie, C-16/19, EU:C:2021:64, punto 33).

$61 \mathrm{Ne}$ consegue che, quando è investita di una questione pregiudiziale vertente sull'interpretazione del principio generale di non discriminazione in base alla religione, quale sancito dall'articolo 21 della Carta, nonché delle disposizioni della direttiva 2000/78, le quali attuano tale articolo 21 e contribuiscono alla realizzazione degli obiettivi del medesimo, nel contesto di una controversia tra un singolo e un'amministrazione pubblica, la Corte esamina tale questione alla luce di tale direttiva (v., in tal senso, sentenza del 13 novembre 2014, Vital Pérez, C-416/13, EU:C:2014:2371, punto 25 e giurisprudenza ivi citata).

62 Ai sensi dell'articolo 2, paragrafo 1, della direttiva 2000/78, per «principio della parità di trattamento» si intende l'assenza di qualsiasi discriminazione diretta o indiretta basata su uno dei motivi di cui all'articolo 1 della stessa direttiva. L'articolo 2, paragrafo 2, lettera a), di detta direttiva precisa che sussiste discriminazione diretta quando, sulla base di uno qualsiasi dei motivi di cui all'articolo 1 della medesima direttiva, tra i quali figura la religione, una persona è trattata meno favorevolmente di quanto lo sia un'altra persona che si trovi in una situazione analoga. A norma dell'articolo 2, paragrafo 2, lettera b), della stessa, sussiste discriminazione indiretta quando una disposizione, un criterio o una prassi apparentemente neutri possono mettere in una posizione di particolare svantaggio le persone che professano una determinata religione rispetto ad altre persone.

63 Inoltre, secondo la giurisprudenza della Corte, dato che la Corte EDU, in particolare nella sua sentenza del 15 maggio 2012, Fernández Martínez c. Spagna (CE:ECHR:2012:0515JUD005603007), e, successivamente, la Carta attribuiscono alla nozione di «religione» un'accezione ampia, poiché includono in tale nozione la libertà per le persone di manifestare la propria religione, si deve ritenere che il legislatore dell'Unione abbia inteso mantenere lo stesso approccio nell'adottare la direttiva 2000/78, cosicché occorre interpretare la nozione di «religione» di cui all'articolo 1 di tale direttiva nel senso che essa comprende sia il forum internum, ossia il fatto di avere convinzioni, sia il forum externum, ossia la manifestazione pubblica della fede religiosa (sentenza del 14 marzo 2017, G 4S Secure Solutions, C-157/15, EU:C:2017:203, punto 28). 
64 Orbene, nel caso di specie, dalla domanda di pronuncia pregiudiziale risulta che la normativa nazionale di cui al procedimento principale priva gli insegnanti di religione cattolica degli istituti di istruzione pubblica, quali i ricorrenti nel procedimento principale, della possibilità di convertire il loro contratto di lavoro a tempo determinato in un contratto di lavoro a tempo indeterminato e/o di ottenere un risarcimento per il danno subìto a causa della successione di contratti a tempo determinato non già in considerazione della loro religione, bensì, al pari degli altri docenti di tali istituti, per il fatto che essi rientrano nel settore dell'insegnamento pubblico. Inoltre, se, a differenza di questi ultimi, essi non hanno beneficiato delle procedure applicabili in forza dell'articolo 399 del decreto legislativo n. 297/1994 né del piano straordinario di assunzioni previsto dalla legge n. 107/2015 non è per questo motivo, ma per via della durata annuale dei loro incarichi, che non consentiva il loro inserimento nelle graduatorie permanenti, il quale era necessario per le immissioni in ruolo avvenute a tali titoli. Infine, una tale durata non ha alcun nesso con il rilascio dell'idoneità e la professione di fede necessari per l'insegnamento della religione cattolica, né con la possibilità di revoca di tale idoneità, giacché tali elementi riguardano anche gli insegnanti di religione cattolica assunti a tempo indeterminato.

65 Pertanto, ammettendo che gli insegnanti di religione cattolica degli istituti di istruzione pubblica si trovino in una situazione analoga a quella dei docenti di altre materie in questi stessi istituti, titolari di un contratto a tempo determinato e che abbiano beneficiato di detto articolo 399 o di detto piano, una simile differenza di trattamento non è fondata sulla religione, ma riguarda soltanto la disciplina applicabile al rapporto di lavoro.

66 Infine, il giudice del rinvio non si è interrogato sull'eventuale sussistenza di una discriminazione indiretta, ai sensi dell'articolo 2, paragrafo 2, lettera b), della direttiva 2000/78, e la domanda di pronuncia pregiudiziale non contiene elementi che consentano di ritenere che il criterio apparentemente neutro previsto nella normativa di cui al procedimento principale metta, di fatto, in una posizione di particolare svantaggio le persone che professano una determinata religione.

67 Tuttavia, come rilevato dalla Commissione, il pregiudizio lamentato dai ricorrenti nel procedimento principale, derivante esclusivamente dall'impossibilità di avvalersi degli strumenti di tutela previsti nel diritto nazionale per sanzionare l'utilizzo abusivo di contratti a tempo determinato, è oggetto di una normativa specifica dell'Unione, ossia quella prevista dall'accordo quadro.

68 Ciò considerato, al fine di fornire una risposta utile al giudice del rinvio per risolvere la controversia di cui è investito, si devono riformulare le questioni pregiudiziali esclusivamente alla luce delle pertinenti disposizioni dell'accordo quadro e ritenere che, con le sue questioni, tale giudice chieda, in sostanza, se la 
clausola 5 dell'accordo quadro debba essere interpretata nel senso che essa osta a una normativa nazionale che esclude gli insegnanti di religione cattolica dall'applicazione delle norme dirette a sanzionare il ricorso abusivo a una successione di contratti a tempo determinato, e se la necessità di un'idoneità rilasciata da un'autorità ecclesiastica costituisca una "ragione obiettiva» ai sensi della clausola 5, punto 1, lettera a), dell'accordo quadro. Nel caso in cui la normativa nazionale non preveda alcuna misura idonea a prevenire, ai sensi della clausola 5, punto 1, dell'accordo quadro, o a sanzionare gli abusi derivanti dall'utilizzo di una successione di contratti o rapporti di lavoro a tempo determinato, detto giudice si chiede se la clausola 4 dell'accordo quadro consenta di disapplicare le norme che impediscono la conversione automatica di un contratto a tempo determinato in un contratto a tempo indeterminato, qualora il rapporto di lavoro si protragga oltre un certo periodo.

69 In via preliminare, si deve ricordare che dalla stessa formulazione della clausola 2, punto 1, dell'accordo quadro risulta che l'ambito d'applicazione di quest'ultimo è concepito in senso ampio, poiché riguarda in generale $\mathrm{i}$ «lavoratori a tempo determinato con un contratto di assunzione o un rapporto di lavoro disciplinato dalla legge, dai contratti collettivi o dalla prassi in vigore di ciascuno Stato membro». Inoltre, la definizione della nozione di «lavorator[i] a tempo determinato» ai sensi della clausola 3, punto 1, dell'accordo quadro include tutti i lavoratori, senza operare distinzioni basate sulla natura pubblica o privata del loro datore di lavoro (ordinanza del 21 settembre 2016, Popescu, C-614/15, EU:C:2016:726, punto 33).

70 Atteso che l'accordo quadro non esclude alcun settore particolare dal suo ambito di applicazione, esso si applica quindi anche al personale assunto nel settore dell'insegnamento impartito presso istituti pubblici (v., in tal senso, sentenza del 26 novembre 2014, Mascolo e a., C-22/13, C-61/13, C-63/13 e C-418/13, EU:C:2014:2401, punto 69).

$71 \mathrm{Ne}$ consegue che lavoratori quali i ricorrenti nel procedimento principale, impiegati dal MIUR e i cui contratti di lavoro sono conclusi a tempo determinato, rientrano nell'ambito di applicazione dell'accordo quadro.

72 Per quanto concerne la clausola 4 dell'accordo quadro, va ricordato che, per costante giurisprudenza, poiché il principio di non discriminazione è stato attuato e concretizzato dall'accordo quadro solo per quanto riguarda le differenze di trattamento tra i lavoratori a tempo determinato e i lavoratori a tempo indeterminato che si trovano in situazioni comparabili, le eventuali differenze di trattamento tra determinate categorie di personale a tempo determinato non rientrano nell'ambito del principio di non discriminazione sancito da detto accordo quadro (v., in tal senso, sentenza del 21 novembre 2018, 
Viejobueno Ibáñez e de la Vara González, C-245/17, EU:C:2018:934, punto 51 e giurisprudenza ivi citata).

73 In particolare, la clausola 4 dell'accordo quadro mira a dare applicazione al principio di non discriminazione nei confronti dei lavoratori a tempo determinato, al fine di impedire che un rapporto di impiego di tale natura venga utilizzato da un datore di lavoro per privare tali lavoratori di diritti riconosciuti ai lavoratori a tempo indeterminato (sentenza del 17 marzo 2021, Consulmarketing, C-652/19, EU:C:2021:208, punto 49 e giurisprudenza ivi citata).

74 Orbene, il fatto che taluni lavoratori a tempo determinato, come i ricorrenti nel procedimento principale, non possano beneficiare di una conversione del loro contratto di lavoro in contratto a tempo indeterminato, mentre altri lavoratori dell'insegnamento pubblico che insegnano altre materie e si trovano in una situazione comparabile potevano farlo, costituisce appunto una differenza di trattamento tra due categorie di lavoratori a tempo determinato.

$75 \mathrm{Ne}$ consegue che, in una situazione del genere, il giudice del rinvio non può disapplicare le norme nazionali che impediscono, nel caso degli insegnanti di religione cattolica degli istituti di istruzione pubblica, la conversione automatica di un contratto a tempo determinato in un contratto a tempo indeterminato qualora il rapporto di lavoro si protragga oltre una certa data sulla base della clausola 4 dell'accordo quadro, dal momento che tale situazione non rientra nell'ambito di tale clausola.

76 Quanto alla clausola 5 dell'accordo quadro, occorre ricordare che tale clausola ha lo scopo di attuare uno degli obiettivi perseguiti dallo stesso, vale a dire delimitare il ripetuto ricorso ai contratti o ai rapporti di lavoro a tempo determinato, considerato come potenziale fonte di abuso a danno dei lavoratori, prevedendo un certo numero di disposizioni di tutela minima volte ad evitare la precarizzazione della situazione dei lavoratori dipendenti (sentenza del 3 giugno 2021, Instituto Madrileño de Investigación y Desarrollo Rural, Agrario y Alimentario, C-726/19, EU:C:2021:439, punto 26 e giurisprudenza ivi citata).

77 Come risulta dal secondo comma del preambolo dell'accordo quadro nonché dai punti da 6 a 8 delle considerazioni generali di detto accordo quadro, infatti, il beneficio della stabilità dell'impiego è inteso come un elemento portante della tutela dei lavoratori, laddove soltanto in alcune circostanze i contratti di lavoro a tempo determinato sono atti a rispondere alle esigenze sia dei datori di lavoro sia dei lavoratori [v., in tal senso, sentenza del 3 giugno 2021, Ministero dell'Istruzione, dell'Università e della Ricerca - MIUR e a. (Ricercatori universitari), C-326/19, EU:C:2021:438, punto 65 e giurisprudenza ivi citata]. 
78 Pertanto, la clausola 5 dell'accordo quadro impone, al suo punto 1, agli Stati membri, al fine di prevenire l'utilizzo abusivo di una successione di contratti o rapporti di lavoro a tempo determinato, l'adozione effettiva e vincolante di almeno una delle misure che essa elenca, qualora il loro diritto interno non contenga norme equivalenti. Le misure così elencate al punto 1, lettere da a) a c), di tale clausola, in numero di tre, attengono, rispettivamente, a ragioni obiettive per la giustificazione del rinnovo di simili contratti o rapporti di lavoro, alla durata massima totale di tali contratti o rapporti di lavoro successivi e al numero massimo di rinnovi di questi ultimi (sentenza del 24 giugno 2021, Obras y Servicios Públicos e Acciona Agua, C-550/19, EU:C:2021:514, punto 45 e giurisprudenza ivi citata).

79 Gli Stati membri dispongono, a tale riguardo, di un margine di discrezionalità, dal momento che possono scegliere di far ricorso a una o più delle misure elencate nella clausola 5, punto 1, lettere da a) a c), dell'accordo quadro oppure a norme equivalenti esistenti. In tal modo la clausola 5, punto 1, dell'accordo quadro assegna agli Stati membri un obiettivo generale, consistente nella prevenzione di simili abusi, lasciando loro al contempo la scelta dei mezzi per conseguirlo, purché essi non rimettano in discussione lo scopo o l'effetto utile di tale accordo quadro (sentenza del 24 giugno 2021, Obras y Servicios Públicos e Acciona Agua, C-550/19, EU:C:2021:514, punto 46 e giurisprudenza ivi citata).

80 Come emerge dalla clausola 5, punto 1, dell'accordo quadro e conformemente al terzo comma del preambolo nonché ai punti 8 e 10 delle considerazioni generali del medesimo, è nell'ambito dell'attuazione dell'accordo quadro che gli Stati membri hanno facoltà, in quanto ciò sia oggettivamente giustificato, di tener conto delle esigenze particolari relative ai settori di attività e/o alle categorie specifici di lavoratori in questione (sentenza del 25 ottobre 2018, Sciotto, C-331/17, EU:C:2018:859, punto 35 e giurisprudenza ivi citata).

81 Inoltre, la clausola 5 dell'accordo quadro non prevede sanzioni specifiche nell'ipotesi in cui siano stati nondimeno constatati abusi. In un caso del genere, spetta alle autorità nazionali adottare misure che siano non soltanto proporzionate, ma altresì sufficientemente effettive e dissuasive da garantire la piena efficacia delle norme adottate in attuazione dell'accordo quadro (v., in tal senso, sentenza del 24 giugno 2021, Obras y Servicios Públicos e Acciona Agua, C-550/19, EU:C:2021:514, punto 47 e giurisprudenza ivi citata).

82 Pertanto, la clausola 5 dell'accordo quadro non enuncia un obbligo generale degli Stati membri di prevedere la trasformazione dei contratti di lavoro a tempo determinato in un contratto a tempo indeterminato. Infatti, la clausola 5, punto 2, dell'accordo quadro lascia, in linea di principio, agli Stati membri il compito di determinare a quali condizioni i contratti o i rapporti di lavoro a tempo determinato vadano considerati come conclusi a tempo indeterminato. Da ciò 
discende che l'accordo quadro non prescrive le condizioni in presenza delle quali si possa fare uso dei contratti a tempo indeterminato (sentenza del 3 giugno 2021, Instituto Madrileño de Investigación y Desarrollo Rural, Agrario y Alimentario, C-726/19, EU:C:2021:439, punto 49 e giurisprudenza ivi citata).

83 D'altra parte, affinché una simile normativa nazionale possa essere considerata conforme all'accordo quadro, l'ordinamento giuridico interno dello Stato membro interessato deve tuttavia prevedere un'altra misura effettiva per prevenire e, se del caso, sanzionare l'utilizzo abusivo di una successione di contratti di lavoro a tempo determinato (sentenza del 24 giugno 2021, Obras y Servicios Públicos e Acciona Agua, C-550/19, EU:C:2021:514, punto 48 e giurisprudenza ivi citata).

84 Ne consegue che, quando si sia verificato un ricorso abusivo a una successione di contratti o rapporti di lavoro a tempo determinato, deve potersi applicare una misura che presenti garanzie effettive ed equivalenti di tutela dei lavoratori al fine di sanzionare debitamente tale abuso e rimuovere le conseguenze della violazione del diritto dell'Unione. Infatti, secondo i termini stessi dell'articolo 2, primo comma, della direttiva 1999/70, gli Stati membri devono "prendere tutte le disposizioni necessarie per essere sempre in grado di garantire i risultati prescritti da [tale] direttiva» (sentenza del 24 giugno 2021, Obras y Servicios Públicos e Acciona Agua, C-550/19, EU:C:2021:514, punto 49 e giurisprudenza ivi citata).

85 Pertanto, si deve ritenere che, nel caso di specie, se risulta che non esiste, nella normativa nazionale di cui al procedimento principale, nessun'altra misura effettiva per prevenire e sanzionare gli abusi eventualmente constatati nei confronti del personale del settore dell'insegnamento pubblico della regione cattolica, una simile situazione sarebbe idonea a pregiudicare l'obiettivo e l'effetto utile della clausola 5 dell'accordo quadro.

86 A tale riguardo, occorre ricordare che non spetta alla Corte pronunciarsi sull'interpretazione delle disposizioni di diritto interno, compito che incombe ai giudici nazionali competenti, i quali devono determinare se le prescrizioni di cui alla clausola 5 dell'accordo quadro siano soddisfatte dalle disposizioni della normativa nazionale applicabile (sentenza del 24 giugno 2021, Obras y Servicios Públicos e Acciona Agua, C-550/19, EU:C:2021:514, punto 50 e giurisprudenza ivi citata).

87 Incombe pertanto, nel caso di specie, al giudice del rinvio valutare entro quali limiti le condizioni per l'applicazione nonché l'effettiva attuazione delle disposizioni rilevanti del diritto interno costituiscano una misura adeguata per prevenire e, se del caso, sanzionare l'utilizzo abusivo di una successione di contratti o rapporti di lavoro a tempo determinato (sentenza del 24 giugno 2021, 
Obras y Servicios Públicos e Acciona Agua, C-550/19, EU:C:2021:514, punto 51 e giurisprudenza ivi citata).

88 Tuttavia la Corte, statuendo su rinvio pregiudiziale, può eventualmente apportare precisazioni per guidare tali giudici nella loro valutazione (sentenza del 19 marzo 2020, Sánchez Ruiz e a., C-103/18 e C-429/18, EU:C:2020:219, punto 91 e giurisprudenza ivi citata).

89 Dall'ordinanza di rinvio emerge, da un lato, che la normativa nazionale di cui al procedimento principale consente l'assunzione, nel settore dell'insegnamento pubblico della religione cattolica, di un gran numero di docenti mediante una successione di contratti di lavoro a tempo determinato, senza prevedere alcuno dei limiti di cui alla clausola 5, punto 1, lettere b) e c), dell'accordo quadro quanto alla durata massima totale di tali contratti o al numero di rinnovi dei medesimi e, dall'altro, che i contratti di lavoro a tempo determinato stipulati in detto settore sono espressamente esclusi dall'ambito di applicazione delle disposizioni nazionali che consentono la conversione di contratti di questo tipo, stipulati in successione oltre una determinata durata, in contratti di lavoro a tempo indeterminato nonché, eventualmente, il risarcimento del danno subìto a seguito di una simile successione.

90 Inoltre, secondo le indicazioni fornite dal giudice del rinvio, i ricorrenti nel procedimento principale non sarebbero neppure destinatari delle procedure applicabili ai sensi dell'articolo 399 del decreto legislativo n. 297/1994 né del piano straordinario di assunzione di docenti a tempo indeterminato istituito dal MIUR, i quali sono stati equiparati dalla Corte a una forma di trasformazione di contratti di lavoro a tempo determinato in contratto a tempo indeterminato (sentenza dell'8 maggio 2019, Rossato e Conservatorio di Musica F. A. Bonporti, C-494/17, EU:C:2019:387, punti da 32 a 36).

91 Ciò premesso, occorre verificare se il ricorso, nel settore dell'insegnamento pubblico della religione cattolica, a una successione di contratti di lavoro a tempo determinato possa essere giustificato dall'esistenza, nel diritto nazionale, di ragioni obiettive, ai sensi della clausola 5, punto 1, lettera a), dell'accordo quadro, e, più in particolare, se il rilascio dell'idoneità da parte dell'ordinario diocesano al fine di consentire all'insegnante di religione cattolica di insegnare tale materia possa costituire una simile ragione obiettiva.

$92 \mathrm{Si}$ deve infatti rilevare che, come indica il punto 7 delle considerazioni generali dell'accordo quadro, le parti firmatarie di quest'ultimo hanno ritenuto che l'utilizzazione di contratti di lavoro a tempo determinato basata su «ragioni obiettive» sia un modo di prevenire gli abusi (sentenza del 3 giugno 2021, Instituto Madrileño de Investigación y Desarrollo Rural, Agrario y Alimentario, C-726/19, EU:C:2021:439, punto 55 e giurisprudenza ivi citata). 
93 Per quanto riguarda la nozione di «ragioni obiettive», ai sensi della clausola 5, punto 1, lettera a), dell'accordo quadro, essa deve essere intesa nel senso che si riferisce a circostanze precise e concrete che contraddistinguono una determinata attività e, pertanto, tali da giustificare, in tale peculiare contesto, l'utilizzo di una successione di contratti di lavoro a tempo determinato. Dette circostanze possono risultare, segnatamente, dalla particolare natura delle funzioni per l'espletamento delle quali sono stati conclusi contratti di tal genere, dalle caratteristiche ad esse inerenti o, eventualmente, dal perseguimento di una legittima finalità di politica sociale di uno Stato membro (sentenza del 24 giugno 2021, Obras y Servicios Públicos e Acciona Agua, C-550/19, EU:C:2021:514, punto 59 e giurisprudenza ivi citata).

$94 \mathrm{Al}$ contrario, una disposizione nazionale che si limitasse ad autorizzare, in modo generale e astratto, attraverso una norma legislativa o regolamentare, il ricorso a una successione di contratti di lavoro a tempo determinato non sarebbe conforme agli obblighi precisati al precedente punto. Infatti, una simile disposizione puramente formale non consente di stabilire criteri oggettivi e trasparenti al fine di verificare se il rinnovo di simili contratti risponda effettivamente a un'esigenza reale, se esso sia idoneo a conseguire l'obiettivo perseguito e sia necessario a tale effetto. La suddetta disposizione comporta dunque un rischio concreto di determinare un ricorso abusivo a tale tipo di contratti e, pertanto, non è compatibile con l'obiettivo e con l'effetto utile dell'accordo quadro (sentenza del 24 giugno 2021, Obras y Servicios Públicos e Acciona Agua, C-550/19, EU:C:2021:514, punti 60 e 61 e giurisprudenza ivi citata).

95 Il governo italiano avanza vari argomenti volti a dimostrare l'esistenza, nel caso di specie, di circostanze precise e concrete tali da giustificare il ricorso a una successione di contratti di lavoro a tempo determinato per gli insegnanti di religione cattolica degli istituti pubblici, circostanze scaturenti principalmente dal rapporto tra la Repubblica italiana e la Santa Sede nonché dalla flessibilità organizzativa richiesta per l'insegnamento della religione cattolica.

96 Per quanto riguarda il primo aspetto, il governo italiano sottolinea, anzitutto, che l'insegnamento della religione cattolica nelle scuole pubbliche è una peculiarità del sistema educativo italiano. Il legame di speciale fiducia che deve esistere tra l'insegnante di tale materia e l'ordinario diocesano comporta la necessaria valutazione del candidato all'insegnamento della religione cattolica da parte del vescovo stesso al fine di impedire che l'insegnamento sia contrario alle prescrizioni dell'accordo concluso tra la Repubblica italiana e la Santa Sede, dando al vescovo diocesano la possibilità di valutare, anno dopo anno, l'idoneità di ciascun insegnante.

97 Tale governo si basa poi sul fatto che un insegnante di religione cattolica potrebbe insegnare tale materia solo in seguito al rilascio dell'idoneità da parte del vescovo 
diocesano, il quale valuta se l'insegnante in questione presenti i requisiti previsti dal diritto canonico e se tale idoneità possa essere mantenuta nel tempo. A questo proposito, il governo italiano precisa che la «ragione obiettiva», ai sensi della clausola 5, punto 1, lettera a), dell'accordo quadro, deriverebbe non già dall'eventuale revoca di una simile idoneità, bensì dalla necessità di rispettare il Concordato nonché di dispensare un insegnamento della religione cattolica che sia conforme ai suoi principi, in particolare al fine di soddisfare le aspettative degli alunni e dei loro genitori.

98 Inoltre, concorrendo, conformemente al Concordato, in piena autonomia, in particolare alla determinazione dei profili degli insegnanti, al riconoscimento della loro idoneità e alla loro designazione, la Chiesa cattolica assumerebbe le responsabilità connesse ai tratti confessionali di un insegnamento nei cui riguardi lo Stato rimane aperto e disponibile ma non diviene partecipe. Quest'ultimo riconoscerebbe il valore della cultura religiosa e terrebbe conto del fatto che i principi del cattolicesimo fanno parte del patrimonio storico italiano, pur mantenendo la distanza propria di uno Stato laico pluralista che non si identificherebbe con nessuna confessione religiosa.

99 Per quanto riguarda il secondo aspetto, il governo italiano afferma che l'elevato numero di contratti a tempo determinato nel settore dell'insegnamento della religione cattolica assicurerebbe la flessibilità conseguente alla facoltatività di tale insegnamento, il che consentirebbe di adeguare il numero necessario di insegnanti semplicemente non rinnovando un dato numero di contratti annuali, anziché risolvendo contratti a tempo indeterminato. Tale approccio, che consentirebbe quindi di rispondere in modo adeguato alla contrazione della domanda di insegnamento della religione cattolica dovuta a detta facoltatività, sarebbe approvato dalla Corte costituzionale e costituirebbe, inoltre, un'espressione della salvaguardia degli interessi finanziari e organizzativi dello Stato.

100 Per quanto attiene, in primo luogo, all'argomento relativo al legame di speciale fiducia che deve esistere tra l'insegnante di religione cattolica e il vescovo diocesano, è sufficiente constatare che tale legame riguarda tanto gli insegnanti che hanno stipulato un contratto a tempo indeterminato quanto quelli titolari di un contratto a tempo determinato, sicché tale argomento non può essere invocato per giustificare il ricorso abusivo ai contratti a tempo determinato.

101 Per quanto attiene, in secondo luogo, alla salvaguardia della cultura religiosa e del patrimonio storico italiano, occorre rilevare che, per quanto tale obiettivo possa essere considerato meritevole di tutela costituzionale, il governo italiano non spiega tuttavia come il perseguimento di detto obiettivo possa giustificare l'assunzione del 30\% degli insegnati di religione cattolica per mezzo di contratti a 
tempo determinato (v., in tal senso, sentenza del 25 ottobre 2018, Sciotto, C-331/17, EU:C:2018:859, punto 45).

102 Ciò posto, occorre nondimeno constatare, in terzo luogo, che non è escluso che il settore dell'insegnamento pubblico della religione cattolica richieda un costante adeguamento tra il numero di lavoratori ivi impiegati e il numero di potenziali utenti, come sottolinea il governo italiano, il che comporta, per il datore di lavoro, esigenze provvisorie in materia di assunzione. In tal senso, l'assunzione temporanea di un lavoratore al fine di soddisfare le esigenze provvisorie e specifiche del datore di lavoro in termini di personale può, in via di principio, costituire una «ragione obiettiva» ai sensi della clausola 5, punto 1, lettera a), dell'accordo quadro (sentenza del 25 ottobre 2018, Sciotto, C-331/17, EU:C:2018:859, punto 47).

103 A tale riguardo, il servizio scolastico deve essere organizzato in modo da garantire un adeguamento costante tra il numero di docenti e il numero di alunni. Orbene, non si può negare che tale adeguamento dipenda da un insieme di fattori, taluni dei quali possono, in una certa misura, essere difficilmente controllabili o prevedibili, quali, in particolare, i flussi migratori esterni ed interni o le scelte di indirizzi scolastici da parte degli alunni (v., in tal senso, sentenza del 26 novembre 2014, Mascolo e a., C-22/13, da C-61/13 a C-63/13 e C-418/13, EU:C:2014:2401, punto 94).

104 Fattori del genere attestano, nel settore dell'insegnamento di cui trattasi nel procedimento principale, un'esigenza particolare di flessibilità che, come menzionato al punto 102 della presente sentenza, è idonea, in tale specifico settore, a giustificare oggettivamente, alla luce della clausola 5, punto 1, lettera a), dell'accordo quadro, il ricorso a una successione di contratti di lavoro a tempo determinato per rispondere in maniera adeguata alla domanda scolastica ed evitare di esporre lo Stato, quale datore di lavoro in tale settore, al rischio di dover immettere in ruolo un numero di docenti significativamente superiore a quello effettivamente necessario per adempiere i propri obblighi in materia (sentenza del 26 novembre 2014, Mascolo e a., C-22/13, da C-61/13 a C-63/13 e C-418/13, EU:C:2014:2401, punto 95).

105 Non si può invece ammettere che contratti di lavoro a tempo determinato possano essere rinnovati per la realizzazione, in modo permanente e duraturo, di compiti che rientrano nella normale attività del settore dell'insegnamento. Come più volte statuito dalla Corte, il rinnovo di contratti o di rapporti di lavoro a tempo determinato per far fronte a esigenze che, di fatto, hanno carattere non già provvisorio ma permanente e durevole non è giustificato ai sensi della clausola 5, punto 1, lettera a), dell'accordo quadro, dal momento che un tale utilizzo dei contratti o dei rapporti di lavoro a tempo determinato si scontra direttamente con la premessa sulla quale si fonda il suddetto accordo quadro, vale a dire il fatto 
che i contratti di lavoro a tempo indeterminato costituiscono la forma comune dei rapporti di lavoro, anche se i contratti di lavoro a tempo determinato rappresentano una caratteristica dell'impiego in alcuni settori o per determinate occupazioni e attività (sentenza del 24 giugno 2021, Obras y Servicios Públicos e Acciona Agua, C-550/19, EU:C:2021:514, punto 62 e giurisprudenza ivi citata).

106 L'osservanza della clausola 5, punto 1, lettera a), dell'accordo quadro esige pertanto che sia verificato concretamente che il rinnovo di contratti o rapporti di lavoro a tempo determinato successivi miri a soddisfare esigenze provvisorie, e che una disposizione nazionale come quella di cui al procedimento principale non sia utilizzata, di fatto, per soddisfare esigenze permanenti e durevoli del datore di lavoro in materia di personale (sentenza del 24 giugno 2021, Obras y Servicios Públicos e Acciona Agua, C-550/19, EU:C:2021:514, punto 63 e giurisprudenza ivi citata).

107 Occorre a tal fine esaminare di volta in volta tutte le circostanze del caso, prendendo in considerazione, in particolare, il numero di detti contratti successivi stipulati con la stessa persona oppure per lo svolgimento di uno stesso lavoro, al fine di escludere che contratti o rapporti di lavoro a tempo determinato, sebbene apparentemente conclusi per soddisfare un'esigenza di personale sostitutivo, siano utilizzati in modo abusivo dai datori di lavoro (sentenza del 24 giugno 2021, Obras y Servicios Públicos e Acciona Agua, C-550/19, EU:C:2021:514, punto 64 e giurisprudenza ivi citata).

108 L'esistenza di una «ragione obiettiva» ai sensi della clausola 5, punto 1, lettera a), dell'accordo quadro esclude quindi, in linea di principio, l'esistenza di un abuso, a meno che un esame globale delle circostanze sottese al rinnovo dei contratti o dei rapporti di lavoro a tempo determinato di cui trattasi riveli che le prestazioni richieste al lavoratore non corrispondono a una mera esigenza temporanea (sentenza del 26 novembre 2014, Mascolo e a., C-22/13, da C-61/13 a C-63/13 e C-418/13, EU:C:2014:2401, punto 103).

109 Di conseguenza, il solo fatto che la normativa nazionale di cui trattasi nel procedimento principale possa essere giustificata da una «ragione obiettiva» ai sensi di tale disposizione non può essere sufficiente a renderla ad essa conforme, se risulta che l'applicazione concreta di detta normativa conduce, nei fatti, a un ricorso abusivo a una successione di contratti di lavoro a tempo determinato (sentenza del 26 novembre 2014, Mascolo e a., C-22/13, da C-61/13 a C-63/13 e C-418/13, EU:C:2014:2401, punto 104).

110 Orbene, da un lato, la normativa nazionale di cui al procedimento principale non subordina ad alcuna condizione di tale natura la deroga da essa introdotta alle norme di diritto comune applicabili ai contratti di lavoro e intese a sanzionare il ricorso abusivo a una successione di contratti a tempo determinato. Dall'altro, la 
conclusione dei contratti di lavoro in successione di cui al procedimento principale non sembra rispondere a mere esigenze provvisorie del datore di lavoro, ma sembra piuttosto rientrare nelle necessità della gestione ordinaria del medesimo. Per di più, i diversi contratti di lavoro a tempo determinato con i quali i ricorrenti nel procedimento principale sono stati assunti hanno dato luogo allo svolgimento di mansioni simili, se non identiche, per svariati anni, cosicché si può ritenere che tali rapporti di lavoro abbiano soddisfatto un fabbisogno non già provvisorio, bensì, al contrario, duraturo, circostanza che spetta tuttavia al giudice del rinvio verificare.

111 Per quanto riguarda, in quarto luogo, l'argomento relativo agli interessi finanziari dello Stato, va ricordato che la Corte ha già dichiarato che, sebbene considerazioni di bilancio possano costituire il fondamento delle scelte di politica sociale di uno Stato membro e influenzare la natura o la portata delle misure che esso intende adottare, esse non costituiscono tuttavia, di per sé, un obiettivo perseguito da tale politica e, pertanto, non possono giustificare l'assenza di qualsiasi misura di prevenzione del ricorso abusivo a una successione di contratti di lavoro a tempo determinato ai sensi della clausola 5, punto 1, dell'accordo quadro (sentenza del 25 ottobre 2018, Sciotto, C-331/17, EU:C:2018:859, punto $55)$.

112 Per quanto riguarda, in quinto luogo, la questione se la necessità del rilascio dell'idoneità di cui devono essere titolari gli insegnanti di religione cattolica per insegnare tale materia possa costituire una «ragione obiettiva» ai sensi della clausola 5, punto 1, lettera a), dell'accordo quadro, si deve constatare che dal fascicolo di cui dispone la Corte risulta che tale idoneità è rilasciata una sola volta, nel momento in cui l'autorità scolastica presenta il proprio elenco di candidati, e a prescindere dalla durata dell'incarico affidato all'insegnante di religione cattolica in questione. Il rilascio di detta idoneità a tutti gli insegnanti di religione cattolica, indipendentemente dal fatto che essi abbiano stipulato un contratto a tempo indeterminato o un contratto a tempo determinato, costituisce quindi, come già indicato al punto 64 della presente sentenza, un aspetto indipendente dalla durata degli incarichi affidati agli insegnanti di religione cattolica.

113 Analogamente, la revoca dell'idoneità costituisce una causa di risoluzione del rapporto di lavoro sia per gli insegnanti di religione cattolica immessi in ruolo sia per quelli che, come i ricorrenti nel procedimento principale, sono titolari solo di un contratto a tempo determinato, e non costituisce quindi una «ragione obiettiva» ai sensi della clausola 5, punto 1, lettera a), dell'accordo quadro.

114 Infine, poiché il rilascio dell'idoneità non presenta alcun nesso con l'istituzione di misure riconosciute come volte a perseguire obiettivi legittimi di politica sociale come quelle, ad esempio, dirette alla tutela della gravidanza e della 
maternità o alla conciliazione tra la vita professionale e la vita familiare, esso non può essere considerato funzionale al perseguimento di un obiettivo di politica sociale, atteso che la nozione di «ragione obiettiva» di cui alla clausola 5, punto 1, lettera a), dell'accordo quadro comprende, come risulta dalla giurisprudenza ricordata al punto 93 della presente sentenza, il perseguimento di un simile obiettivo (v., in tal senso, sentenza del 26 novembre 2014, Mascolo e a., C-22/13, da C-61/13 a C-63/13 e C-418/13, EU:C:2014:2401, punti 92 e 93 e giurisprudenza ivi citata).

115 Ne consegue che l'idoneità non costituisce una «ragione obiettiva» ai sensi della clausola 5, punto 1, lettera a), dell'accordo quadro.

116 Pertanto, e sempreché non esistano «norme equivalenti per la prevenzione degli abusi», ai sensi della clausola 5, punto 1, dell'accordo quadro, circostanza questa che spetta al giudice del rinvio verificare, una normativa nazionale come quella di cui al procedimento principale nel settore dell'insegnamento pubblico della religione cattolica non è idonea a prevenire o a sanzionare gli abusi derivanti dall'utilizzo di una successione di contratti o rapporti di lavoro a tempo determinato.

117 A tale riguardo, spetta alle autorità giurisdizionali dello Stato membro interessato garantire il rispetto della clausola 5, punto 1, dell'accordo quadro, vegliando a che i lavoratori i quali abbiano subito un abuso in conseguenza dell'utilizzo di una successione di contratti di lavoro a tempo determinato non siano dissuasi, nella speranza di continuare a lavorare nel settore determinato, dal far valere dinanzi alle autorità nazionali, ivi incluse quelle giurisdizionali, $\mathrm{i}$ diritti derivanti dall'attuazione, da parte della normativa nazionale, di tutte le misure preventive di cui alla clausola 5, punto 1, dell'accordo quadro (sentenza del 25 ottobre 2018, Sciotto, C-331/17, EU:C:2018:859, punto 68 e giurisprudenza ivi citata).

118 In particolare, spetta al giudice adito, quanto più possibile e qualora si sia verificato un utilizzo abusivo di una successione di contratti di lavoro a tempo determinato, interpretare e applicare le pertinenti disposizioni di diritto interno in modo da sanzionare debitamente tale abuso e da eliminare le conseguenze della violazione del diritto dell'Unione [sentenza dell'11 febbraio 2021, M. V. e a. (Successione di contratti di lavoro a tempo determinato nel settore pubblico), C-760/18, EU:C:2021:113, punto 69 e giurisprudenza ivi citata].

119 Nel caso di specie, dal momento che la normativa nazionale di cui al procedimento principale contiene norme applicabili ai contratti di lavoro di diritto comune dirette a sanzionare il ricorso abusivo a una successione di contratti a tempo determinato, prevedendo la conversione automatica di un contratto a tempo determinato in un contratto a tempo indeterminato qualora il 
rapporto di lavoro perduri oltre un certo periodo, un'applicazione di tali norme nel procedimento principale potrebbe costituire una misura preventiva di un simile abuso, ai sensi della clausola 5 dell'accordo quadro.

120 Ciò premesso, occorre tuttavia ricordare che la Corte ha statuito che la clausola 5 , punto 1, dell'accordo quadro non è incondizionata e sufficientemente precisa da poter essere invocata da un singolo dinanzi a un giudice nazionale. Una tale disposizione del diritto dell'Unione, priva di effetto diretto, non può quindi essere fatta valere, in quanto tale, nell'ambito di una controversia rientrante nel diritto dell'Unione, al fine di escludere l'applicazione di una disposizione di diritto nazionale ad essa contraria. Pertanto, un giudice nazionale non è tenuto a disapplicare una disposizione di diritto nazionale contraria a detta clausola (sentenza del 24 giugno 2021, Obras y Servicios Públicos e Acciona Agua, C-550/19, EU:C:2021:514, punto 75 e giurisprudenza ivi citata).

121 Ciò precisato, occorre ricordare che, nell'applicare il diritto interno, i giudici nazionali devono interpretarlo quanto più possibile alla luce del testo e dello scopo della direttiva in questione, onde conseguire il risultato perseguito da quest'ultima e conformarsi pertanto all'articolo 288, terzo comma, TFUE (sentenza del 24 giugno 2021, Obras y Servicios Públicos e Acciona Agua, C-550/19, EU:C:2021:514, punto 76 e giurisprudenza ivi citata).

122 L'obbligo di interpretazione conforme del diritto nazionale è infatti inerente al sistema del Trattato FUE, in quanto permette ai giudici nazionali di assicurare, nell'ambito delle rispettive competenze, la piena efficacia del diritto dell'Unione quando risolvono le controversie ad essi sottoposte [sentenza dell'11 febbraio M. V. e a. (Successione di contratti di lavoro a tempo determinato nel settore pubblico), C-760/18, EU:C:2021:113, punto 66 e giurisprudenza ivi citata].

123 Certamente, l'obbligo per il giudice nazionale di fare riferimento al contenuto di una direttiva nell'interpretazione e nell'applicazione delle norme pertinenti del suo diritto interno trova il proprio limite nei principi generali del diritto, in particolare in quelli di certezza del diritto e di non retroattività, e non può servire da fondamento a un'interpretazione contra legem del diritto nazionale (sentenza del 24 giugno 2021, Obras y Servicios Públicos e Acciona Agua, C-550/19, EU:C:2021:514, punto 77 e giurisprudenza ivi citata).

124 Il principio di interpretazione conforme richiede nondimeno che i giudici nazionali facciano tutto quanto compete loro, prendendo in considerazione il diritto interno nella sua interezza e applicando i metodi di interpretazione riconosciuti da quest'ultimo, al fine di garantire la piena efficacia della direttiva di cui trattasi e pervenire a una soluzione conforme allo scopo perseguito da quest'ultima (sentenza del 24 giugno 2021, Obras y Servicios Públicos e Acciona Agua, C-550/19, EU:C:2021:514, punto 78 e giurisprudenza ivi citata). Pertanto, 
spetta al giudice del rinvio verificare se una simile interpretazione conforme delle disposizioni nazionali sia possibile.

125 Alla luce di tutte le considerazioni che precedono, occorre rispondere alle questioni pregiudiziali poste dichiarando che la clausola 5 dell'accordo quadro deve essere interpretata nel senso, da un lato, che essa osta a una normativa nazionale che esclude gli insegnanti di religione cattolica degli istituti di insegnamento pubblico dall'applicazione delle norme dirette a sanzionare il ricorso abusivo a una successione di contratti a tempo determinato, qualora non esista nessun'altra misura effettiva nell'ordinamento giuridico interno che sanzioni detto ricorso abusivo, e, dall'altro, che la necessità di un titolo di idoneità rilasciato da un'autorità ecclesiastica al fine di consentire a tali insegnanti di impartire l'insegnamento della religione cattolica non costituisce una «ragione obiettiva» ai sensi della clausola 5, punto 1, lettera a), dell'accordo quadro, nella misura in cui tale titolo di idoneità è rilasciato una sola volta, e non prima di ogni anno scolastico che dà luogo alla stipulazione di un contratto di lavoro a tempo determinato.

\section{Sulle spese}

126 Nei confronti delle parti nel procedimento principale la presente causa costituisce un incidente sollevato dinanzi al giudice nazionale, cui spetta quindi statuire sulle spese. Le spese sostenute da altri soggetti per presentare osservazioni alla Corte non possono dar luogo a rifusione.

Per questi motivi, la Corte (Seconda Sezione) dichiara:

La clausola 5 dell'accordo quadro sul lavoro a tempo determinato, concluso il 18 marzo 1999, che figura in allegato alla direttiva 1999/70/CE del Consiglio, del 28 giugno 1999, relativa all'accordo quadro CES, UNICE e CEEP sul lavoro a tempo determinato, deve essere interpretata nel senso, da un lato, che essa osta a una normativa nazionale che esclude gli insegnanti di religione cattolica degli istituti di insegnamento pubblico dall'applicazione delle norme dirette a sanzionare il ricorso abusivo a una successione di contratti a tempo determinato, qualora non esista nessun'altra misura effettiva nell'ordinamento giuridico interno che sanzioni detto ricorso abusivo, e, dall'altro, che la necessità di un titolo di idoneità rilasciato da un'autorità ecclesiastica al fine di consentire a tali insegnanti di impartire l'insegnamento della religione cattolica non costituisce una «ragione obiettiva» ai sensi della clausola 5, punto 1, lettera a), di tale accordo quadro, nella misura in cui tale titolo di idoneità è rilasciato una sola volta, e non prima di ogni anno scolastico che dà luogo alla stipulazione di un contratto di lavoro a tempo determinato.

Firme 